\title{
The phonology of Classical Greek meter*
}

CHRIS GOLSTON and TOMAS RIAD

\begin{abstract}
We propose an analysis of Greek meter based purely on phonology and the idea that well-formedness in meter is largely gradient, rather than absolute. Our analysis is surface-true, constraint-based and nonderivational, in line with proposals like optimality theory (Prince and Smolensky 1993). The discussion centers on two properties of meter, rhythm (dactylic, anapestic, iambic...) and line length (hexameter, pentameter, tetrameter...). Unmarked meters are expected to be binary (dimeter) and rhythmic (no clash or lapse). We analyze individual meters in terms of how they deviate from this unmarked state, where deviations (big and small) are encoded directly as constraint violations following Golston (1996). Greek anapests are shown to be unmarked in terms of rhythm, while dactyls distinctively violate the constraint NOCLASH and iambs distinctively violate NOLAPSE. Similarly, dimeter is unmarked in terms of binarity, while trimeter, tetrameter, pentameter, and hexameter violate constraints on binarity.
\end{abstract}

\section{Introduction}

"Since all metric phenomena are language phenomena, it follows that metrics is entirely within the competence of linguistics" (Lotz 1960: 137). In this paper we take this charge quite seriously and try to describe the major components of classical Greek meter purely in terms of phonology. Since markedness plays a central role in phonology, we try to directly incorporate markedness into the theory of metrics as well.

Specifically, we propose an analysis of Greek spoken meter based on the idea that metrical well-formedness is gradient rather than absolute (Halle and Keyser 1971; Youmans 1989; Golston and Riad 1997; Golston 1998; Hayes and McEachern 1998). In line with recent work in optimality 
theory (Prince and Smolensky 1993; McCarthy and Prince 1993a, 1993b, 1993c), our account is constraint-based and nonderivational. From direct OT (Golston 1996) we adopt the idea that violations of markedness can be distinctive and show that Greek meters are most succinctly described directly in terms of how phonologically marked they are.

We focus on two properties of meter, the rhythmic part (iambic, trochaic, etc.) and the length part (tetrameter, pentameter, etc.). In the unmarked case we expect a meter to be completely rhythmic and completely binary. But where a literary tradition employs more than one meter, as is the case with Greek, there can only be one meter that is unmarked. The rest must be marked in some way, and we propose that the ways in which they are marked are the defining properties of those meters.

We show that some Greek meters are rhythmic while others are not. Specifically, Greek anapestic meter is rhythmic because it manifests a perfect succession of trochaically grouped moras. This means that meters that are not anapestic must be arrhythmic one way or another. We show that dactylic meter is marked by constant stress clash and that iambic meter is marked by constant stress lapse; these meters, then, are rhythmically marked, not rhythmically perfect like the anapest. ${ }^{1}$ We are not the first to argue that meter need not be rhythmic. Similar claims have been made for meters in Tohono O'odham (Fitzgerald 1998), Old English (Getty 1998; Golston and Riad 1998), and Japanese (Kozasa 1998). But we may be the first to claim that arrhythmy can be the defining property of a given meter. In any case, our analysis of Greek meters diverges crucially from traditional and generative analyses in this respect. These analyses treat every Greek meter as rhythmic. The idea that each of these meters is just rhythmic in a different way is demonstrably wrong; we provide the demonstration and reject such analyses.

We also show that some Greek meters are more binary than others. We base our analysis of metrical structure directly on the prosodic hierarchy (Selkirk 1978, 1980, 1981, 1986, 1995; Nespor and Vogel 1982, 1986; Hayes 1989) and assume that metrical structure bears a strict relation to the prosodic structure of natural language (Jakobson 1933, 1952; Kiparsky 1975, 1977; Nespor and Vogel 1986: chapter 10; Hayes 1989; Helsloot 1995, 1997; Golston and Riad 1997; Golston 1998). Specifically, we propose that Greek dimeter is unmarked in terms of binarity while Greek trimeter, tetrameter, pentameter, and hexameter distinctively violate one or more constraints on binarity.

Our overall approach, then, is twofold. First, we parse the text into the feet that Greek made use of (the moraic trochee), assign prominence accordingly, and see which meters are rhythmic, which are not, and to 
what degree. This covers the traditional notions anapest, dactyl, iamb, and spondee. Second, we group these moraic trochees by twos into hierarchical structures until we arrive at a single tree for each line and see which meters are binary, which are not, and to what degree. This covers the traditional notions dimeter, trimeter, tetrameter, pentameter, and hexameter. We then analyze completely rhythmic and binary meters as unmarked (anapestic dimeter) and analyze arrhythmic (dactylic, iambic, spondaic) and nonbinary meters (trimeter, etc.) as prosodically marked, describing them in terms of the constraints on rhythm and binarity that they violate. Some of these constraints are operative in the nonmetrical phonology of Greek, some are operative only in the nonmetrical phonologies or other languages; but we have tried to do without purely metrical constraints that have no relation to phonology.

Burling's discussion of English meter foreshadows our approach by some 30 years. Burling uncovered a common four-beat metrical pattern in children's verse in a number of unrelated languages and proposed that this pattern was part of our common humanity. He went on to note that much adult poetry does not fit this scheme and attributed the difference essentially to markedness.

More sophisticated English verse has been predominantly interpreted as iambic pentameter - ten syllables to the line divided among five feet with a stress on the second syllable of each foot. [...] To the extent that such verse cannot be simultaneously interpreted as having four isochronic beats to the line, then it is probably difficult and unnatural, and requires special study to be appreciated. Its very difficulty makes iambic pentameter less tedious, and probably permits its use on occasions when the more popular and, in the literal sense of the word, "vulgar" four-beat lines would be out of place. I would make a claim, then, that goes precisely counter to the repeated assertion that iambic pentameter is somehow the "natural" mode of expression in English poetry. I believe instead that it is rather a mode that many English speakers never master and that probably always has to be explicitly taught. All English speakers probably master the fourbeat line with no special instruction, and that would seem to make it the more "natural" verse form (Burling 1966: 1426).

Greek anapestic dimeter is unmarked in the same way as children's verse, and other Greek meters can profitably be described in terms of how much they deviate from anapestic dimeter, just as pentameter can profitably be described in terms of how much it deviates from a four-beat line. The main parameters of variation are rhythm (anapests are unmarked, dactyls, iambs, and spondees are marked) and length (dimeter is unmarked, trimeter, tetrameter, and so on are marked). The units of measurement for this variation are violations of prosodic constraints. 
The paper proceeds as follows. We begin with some background on meter in general and on Greek meter in particular (section 1). Sections $2-5$ contain analyses of the basic anapestic, dactylic, iambic, and spondaic meters. Section 6 looks in more depth at describing meters in terms of constraints and constraint violations. Section 7 compares our model with previous models of Greek meter, and section 8 offers a short conclusion.

\section{Background}

We intend this study to be part of a larger cross-linguistic study of poetic meter. For this reason we will draw on a number of important generalizations about meters outside of the Greek tradition. We begin with what we believe to be general properties of meter and then move on to things that are characteristic of Greek meters.

\subsection{Poetic meter}

Poetic meter is generally identifiable from prosodic regularities involving phrasing, quantity, and rhythm (Hayes 1988). Regular prosodic patterns of this kind are not normally found in prose (or speech) and one of the major tasks in metrics is to specify how it is that meter sets itself apart from prose. We assume that both prose and poetry place most emphasis on meaning, that is, on the semantics. ${ }^{2}$ Prose and poetry seem to part ways in whether it is syntax or phonology that gets first crack at interpreting the semantics.

Following Golston (1995) and Rice and Svenonius (1997) we model the normal case in language (speech, prose) using a grammar in which syntactic constraints outrank prosodic ones (see Prince and Smolensky 1993 for a formal account of constraint ranking).

(1) prose syntax $\gg$ prosody

Take for example a sentence from a recent article in the Los Angeles Times.

Infants who sleep in a room illuminated with night lights or full lighting are at substantially greater risk of becoming nearsighted than those who sleep in the dark, researchers from the University of Pennsylvania report in today's Nature.

The syntax here is foremost and the text is structured in a way that puts the message out clearly; how the text sounDs is of secondary importance. The syntax outranks the phonology in interpreting the semantics. 
Poetic meter seems to reverse this natural order of things such that How the text sounds becomes primary and what syntactic and morphological structures are used becomes secondary. In metered texts the phonology outranks the syntax in interpreting the semantics, and prosodic concerns become even more important than syntactic concerns (Golston and Riad 1995; Rice 1997a, 1997b, 1997c; Golston 1998; but see Fitzgerald 1994). In more traditional terms, art "is the activity of caring about the look or sound of what we bring into being" (Dover 1997: 22-23) and meter is an art form that cares about sound. We formalize this commonsense understanding as constraint reranking.

\section{(2) poetry prosody $\gg$ syntax}

The idea is that prosodic concerns are given unusually privileged status in poetic meter, such that recurrent prosodic patterns emerge in the speech stream. Syntactic patterns surface as best they can but are sometimes distorted to allow the prosodic patterns to emerge unscathed. Although we will pursue this in a somewhat formalist fashion, we want to stress that this is a common notion of what meter is. It is in fact a common characterization of the very Greek meters we will be looking at.

A sung text was poetry. A spoken text was recognized as poetry if it was organized rhythmically in one or other of a limited number of familiar rhythmical units, i.e. metres. Except (some of the time) in comic dialogue, such a text also differed significantly from everyday conversation, oratory, narrative, or instruction in its vocabulary, morphology and syntax. These linguistic features, however, were not the primary differentia of poetry (Dover 1997: 182).

(For discussion or morphosyntactic differences between poetry and prose in Greek, cf. Dover [1997: chapter 6] and Bers [1984].)

There are at least two broad areas in which to see the primacy of prosody over other parts of grammar: in the prosodic structure of a line and in the violated syntax and morphology often found in metered text.

Looked at from a cross-linguistic perspective, the defining properties of meter are clearly prosodic, not syntactic or morphological. Every meter we have encountered is based on prosodic regularities, not morphosyntactic ones: lines have a set number of syllables; or alternate stresses in a given way; or include words with like syllable onsets (alliteration); and so on. But we do not find meters that are marked by syntactic or morphological regularities. We have never found a meter than runs ABABABABABCC, where $\mathrm{A}$ is an intransitive clause, $\mathrm{B}$ is transitive and $\mathrm{C}$ is ditransitive; or a meter in which odd-numbered lines have masculine gender and even-numbered lines have feminine gender; or anything of 
this sort. Rather, all poetry, wherever we find it, regulates how speech sounds and often does so at the expense of normal lexis and word order.

Recent work in metrics has uncovered a recurrent pattern of binarity among most meters (Burling 1966; Hayes 1988, 1989; Prince 1989), and this binarity seems to extend all the way up the prosodic hierarchy (Helsloot 1995, 1997; Golston 1998; Getty 1998). The prosodic hierarchy includes the phonological foot $(\phi)$, the prosodic word (Wd), the phonological phrase $(\mathrm{Ph})$, and the intonational phrase (Int). ${ }^{3}$ With these four levels of structure we get a basic phonological structure with eight feet, four words, two phrases and one intonational phrase.

(3) The prosodic hierarchy under binarity

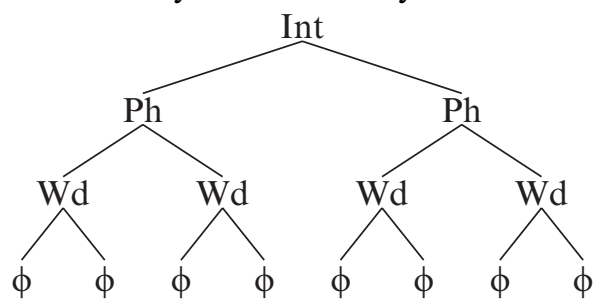

Precisely this binary structure is posited as the basic metrical pattern for a large number of meters in a wide array of languages. It has been proposed for meters in Old English (Creed 1990; Stockwell and Minkova 1997), Middle English (Golston 1998), Modern English (Hayes 1988, 1989), and Early Germanic (Golston and Riad 1998); eighteenth- and nineteenth-century Russian poetry (Friedberg 1997); and nursery rhymes in a number of unrelated languages (Burling 1966). In metrics these prosodic constituents are known as the line, the metron, the verse foot (VF), and the metrical position (M).

(4) Metrical equivalents of the prosodic hierarchy

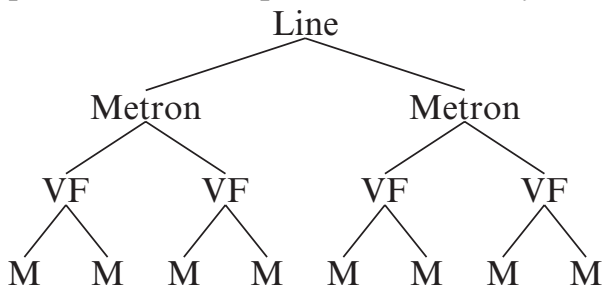

We will use the prosodic and metrical terms interchangeably, but the metrical units are to be understood as dependent on the phonological ones. ${ }^{4}$

It is perhaps worth emphasizing that we equate the verse foot with the prosodic word $(\mathrm{Wd})$, not with the phonological foot. The distinction 
could not be more clear in Greek. The phonological foot is bimoraic for all of Classical Greek, either a single heavy syllable or two lights, a fact that can be established without reference to meter. The nature of the Greek foot is evident from the location of the pitch accent (Allen 1973) and the existence of a bimoraic minimal root and word requirement (Golston 1990, 1991). The verse foot (Wd), on the other hand, varies from meter to meter in Greek; it is one thing for dactylic meter, quite another for iambic or anapestic meter. The fact that Greek had a number of verse feet (anapest, dactyl, trochee, spondee) but only a single phonological foot (moraic trochee) shows us that the feet used in meter and the feet used in phonology and prosodic morphology MUST BE distinct. Following Golston and Riad $(1995,1997)$ we assume that a verse foot is universally a pair of phonological feet, thus that a Greek verse foot is a pair of moraic trochees.

The trees in (3) and (4) are readily described with three constraints on binarity.

(5) INTBIN

(6) PHBIN

Intonational phrases (lines) branch once.

(7) WDBIN

Phonological phrases (metra) branch once.

Phonological words (verse feet) branch once.

If one speaks in accordance with (5)-(7) one will speak in phrases like (3) and (4). We propose that ranking prosody above syntax brings these latent binary structures to the fore in poetic meter. We will show below that there is a Greek meter - anapestic dimeter — that corresponds to this unmarked type and we will show that all other Greek meters can profitably be described in terms of how much they deviate from this normative structure.

Something has to guarantee, of course, that the structures in (3) and (4) are filled with text and not left empty, just as something must guarantee that extra text is not added in addition to what (3) and (4) can accomodate. Following Prince and Smolensky (1993) we use the faithfulness constraints FILL and PARSE for this purpose.

(8) FILL

Syllable positions must be filled with underlying segments.

(9) PARSE

Underlying segments must be parsed into syllable structure.

We are using these constraints in a slightly different way than Prince and Smolensky intend, but we hope that the parallel is clear enough; Helsloot 
(1995: 144ff.) and Hayes and McEachern (1998: 490) use these constraints in the same way. If a given text has less material in it than the prosody requires we register a violation of FILL; the unfilled metrical positions are traditionally said to be catalectic. If a given text has more material in it than the meter allows we register a violation of PARSE; the unparsed text is traditionally said to be extrametrical.

The second place we see prosody at work in meter is when syntax and morphology are distorted metri causa. A well-studied case involves prosodically governed syntactic inversion in Shakespeare and Milton (Youmans 1983, 1989; Rice 1997c). By comparing the syntax of Milton's prose and poetry, Youmans has shown that marked syntactic structures in poetry are often done because of the meter. Consider the following. The basic word order for nouns and adjectives in Milton's prose is [adjective + noun], for example bright guardians; but in his meter one regularly finds [noun + adjective] as well when the prosody requires it: guardians bright (Paradise Lost 3.512). Again, in Milton's prose one finds the standard order [verb + predicate adjective], for example seemed worthy; but in his meter rhythmic constraints hold sway and we find the reverse order as well, worthy seemed (Paradise Lost 4.291). In both cases the inversion is prosodically driven - inversion keeps stressed syllables out of stressless positions. Prosodically driven inversion makes it plain that prosodic concerns in meter can force syntactic constraints to be violated, thus that at least some prosody outranks at least some syntax in poetic meter.

Similar data is less easy to come by in Greek because of the relatively free word order in the language. But there is other compelling evidence that makes the same point. The clearest case is the avoidance of hiatus in meter, where a vowel-final word is followed by a vowel-initial word. This is especially true of tragic (Aeschylus, Euripides, Sophocles) and comic (Aristophanes) drama, which strictly avoids it (Maas 1962: 89ff.; West 1982: 14ff.). It is generally true of epic (Homer) as well, but this is somewhat obscured by diachronic considerations. Specifically, older forms of Greek had a [w] that later Greek lost, and many examples of hiatus in Homer arise from a lost intervocalic [w]. Thus older dio:núsou wánaktos 'of the god Dionysus' occurs in later texts as dio:núsou ánaktos with the $[w]$ gone. Some cases of hiatus can be resolved phonologically by deleting one of the two offending vowels, and this is done quite commonly in all types of poetry (Maas 1962; West 1982: 10ff.). But not all vowels are elidable, and when faced with impending hiatus, the poet commonly reworks the line to avoid it. ${ }^{5}$ This is a clear example of ranking prosody over syntax (and word choice) and it is much more common in 
poetry than it is in prose. Thus, one makes a syntactic decision based on phonological considerations, avoidance of onsetless syllables in this case.

Fitzgerald $(1995,1998)$ and Rice $(1997 a)$ argue for the dominance of prosody over morphology as well, using metrical data from Tohono O'odham and Middle English, respectively. Their proposal might be sketched as follows.

$$
\text { poetry prosody } \gg \text { morphology }
$$

Rice's data come from prosodically governed allomorphy in Chaucer's ten-syllable verse. Specifically, Chaucer used two types of participle, an archaic form with initial $y$ - and a modern form without it. The distribution of such forms is governed by the phonology, such that $y$-initial forms are used to keep stressed syllables out of stressless positions.

(11) Chaucerian participles with $y$ -

And had y-tolde the cause of his cominge (Canterbury Tales 1592).

That is, one makes a morphological decision based on phonological considerations, rather than the reverse. Assuming that in the unmarked case morphology outranks phonology (McCarthy and Prince 1993a, 1993b), poetry again involves an artistic reranking of the natural order of constraints.

Fitzgerald's data is similar, involving semantically vacuous reduplication to keep stressed syllables apart or to provide the end of a line with a stressless syllable. Consider the following example (Fitzgerald 1998: 12).

(12) Vacuous reduplication in Tohono O'odham meter wáwai gíwalige weco náhagio $\mathrm{kc}$ in mémelihime rock cinched below mouse CONJ LOC run to repeatedly 'The mouse runs around there below Cinched Rock'

The citation form for 'rock' in O'odham is wai - the wáwai form that appears in the meter has been reduplicated to avoid stress class with the first syllable of gíwalige 'cinched'. Reduplication normally indicates plurity with nouns, but here the reduplication is clearly meaningless and occurs only to mollify the prosody. Again, this suggests that certain prosodic considerations (avoidance of stress clash) outweigh morphological considerations (proper use of a plural marker) in poetic meter, reversing the normal order of things one finds in prose or speech.

Similar prosodic effects on morphology can be found in Greek. A number of words in epic, for instance, can be stretched or shrunk to fit the needs of the meter. The hero Achilles sometimes occurs LLH and 
sometimes LHH with a geminate [1] providing an extra bit of length where the meter requires it. The following cases, which occur only 15 lines apart in the Iliad, illustrate this.

(13) a. Iliad A, 199

$\left(\begin{array}{llll}\mathrm{H} & \mathrm{H}\end{array}\right)(\mathrm{H} \quad \mathrm{L} \mathrm{L})(\mathrm{H} \quad \mathrm{LL}) \quad(\mathrm{H} \mathrm{L} \mathrm{L})(\mathrm{HLL})$

thámbe:sen d' akhileús, metà d' etrápet' autíka d'

astonish \& Achilles around \& turned at once \&

$(\mathrm{H} \mathrm{H})$

égno:

recognized

'and Achilles was astonished; he turned around and immediately recognized [Athena]'

b. Iliad A, 215

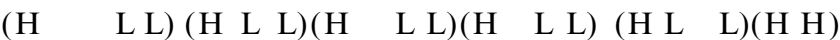
tè:n d' apameibómenos proséphe: pódas o:kùs akhilleús her \& answering spoke feet swift Achilles 'and answering her, swift-footed Achilles spoke'

In the first line Achilles must fit into a LLH sequence, so the second syllable surfaces as light; in the second line Achilles must fit into a LHH sequence, so the second syllables surfaces as long, closed by the geminated [1].

Other squeezable words include Odysseus (long [s] or short) and Olympus (initial monophthong or diphthong).

(14) o.dus.seus o.du.seus

$\mu \mu \mu \quad \mu \mu \quad \mu \quad \mu \mu \mu$

'Odysseus'

$$
\begin{array}{ll}
\text { o.lum.pos } & \text { ou.lum.pos } \\
\mu \mu \mu \quad \mu \mu & \mu \mu \mu \mu \mu \mu
\end{array}
$$

Some words can never be used in epic as is because they have three or more adjacent light syllables; they must be stretched to be usable in the meter at all. Thus $a$ - $t^{h}$ anatos 'immortal' (LLLH) is useless in a meter that requires HH or HLL verse feet, so it shows up as $a:-t^{h}$ anatos with a lengthened [a]. But only in meter. Again, phonological requirements (a heavy syllable) can outrank morphological ones (like respecting the underlying form of a word). 


\subsection{Greek meter}

Turning now to specific properties of Greek meter, it is important to see the ways in which Greek meter differs from modern European meters with which readers may be more familiar.

In many modern European meters a central issue is where lexical stresses go. Children's meter provides examples, as in the following cases from Dr. Seuss, an American author of verse books for children. Trochees line up stresses in stressed-stressless (dum di) pairs; iambs line them up in stressless-stressed (di dum) pairs; and anapests line them up in stressless-stressless-stressed ( $d i d i d u m$ ) triplets, as follows.

(15) English trochees (One Fish Two Fish)

(óne fish) (twó fish) (réd fish) (blúe fish)

(bláck fish) (blúe fish) (óld fish) (néw fish)

(16) English iambs (One Fish Two Fish)

(I dó) (not líke) (this béd) (at áll)

(A lót) (of thíngs) (have cóme) (to cáll)

(A ców) (a dóg), (a cát), (a móuse)

(Oh! whát) (a béd!) (Oh! whát) (a hóuse)!

(17) English anapests (The Cat in the Hat Comes Back)

(But the cát) (just stood stíll)

(He just lóoked) (at the béd).

(This is nót) (the right kínd)

(of a béd) (the cat sáid).

To find patterns in this type of meter, one can learn a lot by looking at where stressed syllables go, and this is common in modern European meters. But this was not how classical Greek meter worked.

First, there is no discernible pattern to where lexical stresses go. The point cannot be made strongly enough, so we quote here from a number of sources.

In English rhythmic "arsis" and "thesis" signify the stressed and the unstressed syllables respectively, a distinction which does not exist in Greek metrics (Maas 1962: section 8).

In English verse (and in that of other modern languages), rhythm is measured by "stress" or "accent". ... In classical Greek (as in Latin) verse, there is a similar division into long and short syllables, but the principle of this division is entirely different, being based on the intrinsic quantity of different vowel-and-consonant combinations. Word accent is of secondary importance, and seems to have played no significant part in the structure of verse (Raven 1962: section 13). 
[I]n Greek there appears to be no attempt to achieve agreement between accent and metre in any part of the line in any spoken form [of meter] (Allen 1973: 262).

In order to find a pattern in Greek meter one has to look past the accented syllables to how syllable weight (quantity) is arranged. A canonical Greek iamb is LH and it does not matter if the L or the H (or both, or neither) gets the primary word stress; anapestic LLH and dactylic HLL can have a lexical stress on any or none of the three syllables. Lexical stress is not what is regulated in Greek meter.

What matters is syllable weight. Not surprisingly, syllable weight in Greek meter is determined just like syllable weight in Greek phonology. Syllables that end in a single short vowel ( $p e, l a$ ) are light; all other syllables are heavy, including those that end in a long vowel (pe:), a diphthong (lai), or a consonant ( pet, lak). For those not familiar with Greek phonology it is worth emphasizing that although heavy syllables are always stressed (Allen 1968, 1973), light syllables are not always stressless. The situation is basically the same as the one we find in Latin or any other language based on moraic trochees (see Hayes 1995). A stress matrix is constituted by one heavy or two light syllables (Allen 1973: 333). Thus we find plenty of stressed light syllables in Greek and a word has as many stresses (primary and secondary) as it has stress matrices. What a word has only one of is pitch accent, a tonal pattern associated with the primary stress (Sauzet 1989); but this pitch accent plays no role in the meter whatsoever.

The second major difference between Greek meter and modern European meters might be termed constancy. Greek iambic meter does not simply run LH.LH.LH, and Greek dactylic meter does not run HLL.HLL.HLL. Despite its name, dactylic meter has almost as many spondaic verse feet (HH) as dactylic ones (HLL). And iambic meter is NOT a simple succession of LH verse feet but includes triads (LLL), dactyls (HLL), and spondees (HH) as well. Anapestic meter uses four kinds of verse foot: canonical anapests ( $\mathrm{LLH})$, spondees $(\mathrm{HH})$, dactyls (HLL), and proceleusmatics (LLLL); and the most common of these is NOT the anapest (LLH) but the spondee $(\mathrm{HH})$, as we will see below. There is only one Greek meter that consistently uses a single verse foot, the spondaic invocation discussed below in section 5, and its status within the tradition is entirely marginal. The common meters of epic, tragedy, and comedy all alternate verse feet within a line. Thus, we will not be able to read Homer and Sophocles the way we read Dr. Seuss, even if we base our dums and dis on quantity (reading dum for $\mathrm{H}$ and $d i$ for $\mathrm{L}$ ) rather than on word stress. 
For this reason it will be very important throughout the following discussion not to read anapests as di di dum or iambs as didum. As has long been noted, such nativizing of the meter in English (or German or Swedish or Russian) is not helpful in understanding purely quantitative meters.

Scarcely any facet of the culture of the ancient world is so alien to us as its quantitative metric. We lack here the most important prerequisite of all historical study; for we can never attain that kind of "empathy" by which all other manifestations of the art, literature, science, philosophy, religion, and social life of the ancients are brought so near to us that they become an essential part of our own culture. ... Our feeling for rhythm is altogether dominated by the dynamic rhythm of our own language and metric. ... We have no means of reading, reciting, or hearing Greek poetry as it actually sounded. It may be possible for us to form a mental notion of it; but such a notion is too shadowy to serve as a basis for the scientific investigation of the subject (Maas 1962: 3-4).

Although we agree that we ought not understand Greek meter in terms of stress, we disagree with the claim that we have no means of reading, reciting, or hearing Greek poetry as it actually sounded. We have a much better understanding of the prosody of Greek now than Maas had earlier in the century (due in great part to Allen 1973 and Devine and Stephens 1994), and we can make use of that understanding in reconstructing the actual texture and rhythm of Greek meter. Our plan, then, is to parse the meter into the feet that Greek used and see what patterns emerge. We find patterns that are much more robust and surface-true than those of previous analyses.

Before turning to individual meters, we need to sketch out a few additional peculiarities of Greek meter. The first is that the final metrical position of any line of Greek meter is a single syllable, $\mathrm{H}$ or $\mathrm{L}$, but never LL, regardless of the meter. Co-opting a term from classics, we shall refer to the final metrical position in a line as anceps. The usual interpretation of final anceps is that the last position must be $\mathrm{H}$, and that $\mathrm{L}$ syllables count as $\mathrm{H}$ in that position. Donca Steriade (personal communication) suggests a less abstract interpretation, where metrical anceps is due to phrase-final lengthening in Greek: $\mathrm{H}$ is long, $\mathrm{L}$ becomes long, ${ }^{6}$ and LL is ruled out because it would be realized as LH. We follow her in this and assume that the metrical fact is linguistically based.

Another important property of Greek meter is that word divisions are completely irrelevant for purposes of syllable quantity. It is as if the entire line were resyllabified without regard to word divisions prior to metrical scansion (Steriade 1982). A phrase like en O.lúm.po: 'on Olympus' might be expected to scan as HLHH since en is a closed syllable 
and thus heavy. But the final [n] of en is syllabified as the onset to the following syllable: e.no.lum.po:, and the phrase ALWAYs scans LLHH. This is very important because it shows that the prosody (beginning with syllable boundaries) is independent of the morphosyntax in meter. This is the most robust effect of the reranking of phonology over syntax: syllabification freely overrides morpheme and word boundaries.

Two other metrical concerns, caesurae and bridges, are important in analyzing Greek meter. A caesura is a point near the center of the line at which one consistently finds a word boundary; as Prince (1989) has shown, caesura tends to occur within one metrical position of the center of the line but not at dead center. A bridge is the opposite, that is, a point in a line at which one rarely finds a word boundary. Caesurae and bridges are important for determining similarities among distinct meters, which can be instrumental in deciding whether a given meter is a shortened (catalectic) version of one meter or another. There is an excellent recent literature on the topic, to which we refer the interested reader (Devine and Stephens 1978, 1981, 1983).

A final peculiarity of Greek line-based meters (on our analysis at least) is that all verse feet end in a bimoraic sequence, $\mathrm{H}$ or LL. Every anapestic, dactylic, iambic, and spondaic foot ends either LL or H. Verse feet that end in a single L are found only in lyric (sung) meters, which form a system of their own, and which fall beyond the scope of this paper. We have no explanation for this fact and will not address it further here.

We are now in a position to delve into some of the details of the Greek meters. We begin with the meter we think is least marked, the anapest.

\section{Anapestic meter}

The Greek anapest comes from the Dorian metrical tradition, where it was originally a marching meter. In drama it is used as the meter for the entrance of the Chorus (Raven 1962: 57) and is commonly used for comic dialogue by Aristophanes; Maas notes that "characters of low social standing [...] are never given lines in sung metres, but are given instead anapests [...] or hexameters" (1962: section 76); it is at once the loosest of the meters and one of the best adapted to the vernacular speech of comedy. For these reasons we think it not unreasonable to treat it as a fairly unmarked meter. But our main reasons for treating the anapest as unmarked is that it comes out that way rhythmically when we read off prominence in terms of moraic trochees, as we will soon see.

Following is a sample from the end of Euripides' Medea. Parentheses here indicate the anapestic verse feet, of which every line has four. Note 
that the last line has only seven metrical positions ( $H$ or LL) rather than the expected eight; the traditional term for this is catalexis. Tradition has it that the final metrical position is catalectic (-), but a moment's thought reveals that this could be otherwise and we will have to seriously consider the possibility that, for example, the initial position of the last line is catalectic instead. We will return to this issue below; for now it will be enough to see that some part of the last line is missing.

(18) Euripides, Medea 1415-1419

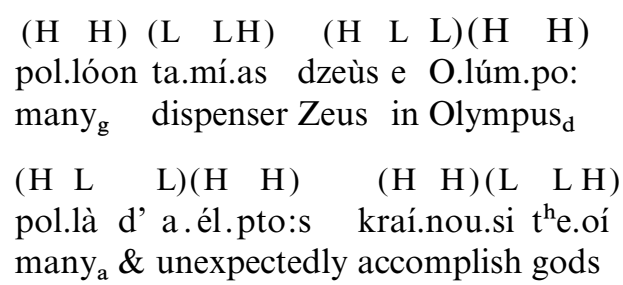

$\left(\begin{array}{lll}\mathrm{H} & \mathrm{L} & \mathrm{L}\end{array}\right)\left(\begin{array}{ll}\mathrm{H} & \mathrm{H}\end{array}\right) \quad\left(\begin{array}{ll}\mathrm{H} & \mathrm{LL}\end{array}\right)\left(\begin{array}{ll}\mathrm{H} & \mathrm{H}\end{array}\right)$

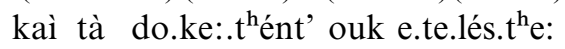
and the presumed not fulfilled

$\left(\begin{array}{llll}\mathrm{H} & \mathrm{L} \mathrm{L}\end{array}\right)(\mathrm{HH}) \quad(\mathrm{L} \mathrm{L} \quad \mathrm{H})(\mathrm{L} \quad \mathrm{LH})$

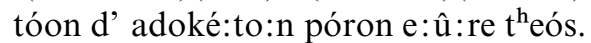
the \& unexpected way finds god

$(\mathrm{HH}) \quad(\mathrm{L} \mathrm{L} \mathrm{H})\left(\begin{array}{lll}\mathrm{L} & \mathrm{L} & \mathrm{H}\end{array}\right)(\mathrm{H}-)$

toi.ónd' apébe: tóde prâgma

so ends this matter

'Olympian Zeus is despenser of many things,

and many are the things the gods do unexpectedly,

and what one thinks will happen does not come to pass,

but a god finds a way to bring about the unexpected.

So ends this matter.'

Before we turn to the matters of length that distinguish the long tetrameter from the short dimeter, we discuss the anapestic part of the meter, for it bears little resemblance to the di di dum that one might expect from reading modern calques. Note the frequent occurrence of $\mathrm{HH}$ and HLL verse feet in the selection alongside the expected LLH, something one never finds in modern European anapests.

This makes the anapest look somewhat chaotic, as if it had no rhythmic properties at all, but this is a result of looking at syllable prominences. As we will see now, the anapestic meter is perfectly rhythmic once we look where the action is in Greek - at the level of the mora. 


\section{1. "Anapestic"}

At the syllable level there is no regular rhythmic pattern in anapestic meter. As the sample above amply demonstrates, the feet are not uniformly LLH. The lack of a uniform pattern of syllable weight means that any syllabic characterization of anapestic as rising, weak/strong, offbeat/beat, or the like is bound to fail. LLH and HLL cannot вотн be rising, weak/strong, etc., because their prominence values in terms of syllable weight are mirror images of one another. The traditional notion of headedness, used to great effect in generative metrics as well, is completely irrelevant here.

To see the true regularity of anapestic meter we must look beyond the superficial alternation of heavy and light syllables to the moraic level. Here, anapestic meter displays a perfectly rhythmic pattern of prominent and nonprominent moras: (x.x.) (x.x.) (x.x.) (x.x.), where 'x' denotes a prominent mora and '? denotes a nonprominent mora. The rhythmic alternation follows from the fact that the phonological foot of Greek is the moraic trochee $(\phi)$, the moras of which are always realized with trochaic prominence - one heavy syllable (the first mora of which is prominent, cf. Kager (1993) or two lights (the first of which is prominent), as shown by Allen (1973). An anapestic verse foot thus has two perfectly rhythmic constituents, $\mathrm{H}$ and LL, each a canonical realization of the moraic trochee (which we henceforth refer to as $\phi$ for 'foot'). Anapestic meters make use of four types of verse foot, each of them consisting of a pair of $\phi$ : LLH, HLL, HH and LLLL. All four types are used in all styles of anapestic meter (West 1982: 191), though to different degrees, and each has its own name in classical scholarship: the anapest proper (LLH), the dactyl (HLL), the spondee (HH), and the proceleusmatic (LLLL).

Looking strictly at the phonology of Greek, prominence falls on all heavy syllables and on the first of two light syllables, as depicted below.

(19) Prominence in anapestic verse feet

$\begin{array}{ccccl}(\mathrm{LL} \mathrm{H}) & (\mathrm{H} \mathrm{LL}) & (\mathrm{H} \mathrm{H}) & (\text { LL LL) } & \\ \text { x. x } & \text { x x. } & \text { x x } & \text { x. x. } & \text { syllable prominence } \\ \text { x. x. } & \text { x. x. } & \text { x. x. } & \text { x. x. } & \text { moraic prominence } \\ \text { anapest } & \text { dactyl } & \text { spondee } & \text { proceleusmatic } & \end{array}$

The second and third lines above show which syllables and moras are prominent (x) and which are not (.). As we have seen, when we assign moraic trochees to the strings in the first row no stable pattern of prominence emerges among the syllables in the second row: LLH is (x.x), 
HLL is (xx.), HH is (xx), and LLLL is (x.x.). But when we look at the pattern of prominence among the moras of the third row, a clear exceptionless pattern emerges. The moraic prominence is utterly regular and rhythmic, a perfect sequence of prominent and nonprominent moras (x.x.), regardless of whether the verse foot is realized as a "true" anapest, a dactyl, a spondee, or a proceleusmatic.

Formally, we can characterize this class of verse feet as the ones that respect a constraint on foot binarity.

(20) FTBIN- $\mu$

Phonological feet (metrical positions) contain two moras.

FTBIN $-\mu$ is related to the other prosodic constraints on binarity considered above in (5)-(7). We call FTBIN- $\mu$ an essential constraint for this type of meter because it serves to define the meter and is never violated.

FTBIN- $\mu$ is a purely linguistic constraint co-opted by the meter. Linguistic evidence for this constraint comes from two sources. The first is the location of the main and secondary stresses in the language, which require a stress matrix of two light syllables or one heavy (Allen 1973), that is, a moraic trochee. The second piece of evidence comes from a strict minimal-root requirement that makes content words in Greek minimally bimoraic (Golston 1990, 1991; Devine and Stephens 1994). Assuming that a metrical position corresponds in the unmarked case to a phonological foot (Golston and Riad 1995, 1997, 1998; Hanson and Kiparsky 1996; Golston 1998), this constraint will rule out those verse feet that contain degenerate feet (a single L syllable) in either position. We should expect this. Binarity is the unmarked case in phonology (Halle and Vergnaud 1980; Kager 1989, 1993; Hayes 1995) as well as in meter (Burling 1966; Hayes 1988; Prince 1989; Golston and Riad 1997; Helsloot 1995, 1997; Golston 1998).

FTBIN- $\mu$ is what makes the four types of anapestic verse foot a natural class. To set this class in relief, consider the range of verse feet allowed in a language with moraic trochees. If a verse foot is a pair of metrical positions (Prince 1989) and if a metrical position is a phonological foot of the language in which the meter is written (Golston and Riad 1995; Hanson and Kiparsky 1996), there are in principle nine distinct types of verse foot available to Greek meter, listed below. ${ }^{7}$

(21) Possible verse feet in a language with moraic trochees

\begin{tabular}{|c|c|c|}
\hline$\left(\begin{array}{ll}H & H\end{array}\right)$ & $\left(\begin{array}{ll}H & L\end{array}\right)$ & $\left(\begin{array}{ll}H & L L\end{array}\right)$ \\
\hline$\left(\begin{array}{ll}\mathrm{L} & \mathrm{H}\end{array}\right)$ & $\left(\begin{array}{ll}L & L\end{array}\right)$ & $\left(\begin{array}{ll}L & L L\end{array}\right)$ \\
\hline$(\mathrm{LL} \mathrm{H})$ & $($ LL L) & (LL LL) \\
\hline
\end{tabular}


Each of these verse feet contains a pair of moraic trochees. These are either canonical two-mora feet (H, LL) or a degenerate one-mora foot (L). Anapestic meter is governed by FTBIN- $\mu$, as we have seen, and thus uses no verse feet with degenerate $\phi$, leaving us with well-formed $\mathrm{HH}$, LLH, HLL, LLLL.

(22) Verse feet used in anapestic meter

\begin{tabular}{|c|c|c|}
\hline$\left(\begin{array}{ll}H & H\end{array}\right)$ & $\left(\begin{array}{ll}H & L\end{array}\right)$ & $\left(\begin{array}{ll}H & L L\end{array}\right)$ \\
\hline$\left(\begin{array}{ll}\mathrm{L} & \mathrm{H}\end{array}\right)$ & $\left(\begin{array}{ll}L & L\end{array}\right)$ & $\left(\begin{array}{ll}L & L L\end{array}\right)$ \\
\hline$(\mathrm{LL} \mathrm{H})$ & (LL L) & (LL LL) \\
\hline
\end{tabular}

The middle row above is excluded from anapestic meter because the first member of each verse foot contains a degenerate foot (L); the middle column is excluded because the second member of each verse foot contains a degenerate foot.

There is a statistical tendency for verse feet in anapestic meter to be realized as HH more often than as LLH, HLL, or LLLL, though the figures are slightly different in tragedy (where LLLL is essentially prohibited) and comedy (where it occurs). Figures in (23) below for tragedy are based on samples from Aeschylus (Prometheus Bound 1080-1094, Seven Against Thebes 1059-1084), Euripides (Medea 1415-1419, Alkestis 1159-1163, Hippolytus 1462-1466, Andromache 1284-1288, Phoenissae 1764-1766, Rhesus 993-996), and Sophocles (Oedipus at Colonus 1760-1779, Antigone 1348-1353); figures for comedy are based on a sampling of Aristophanes (Knights 507-546), which happens to contain no instances of LLLL.

(23) Verse feet in anapestic meters (\%)

Aeschylus

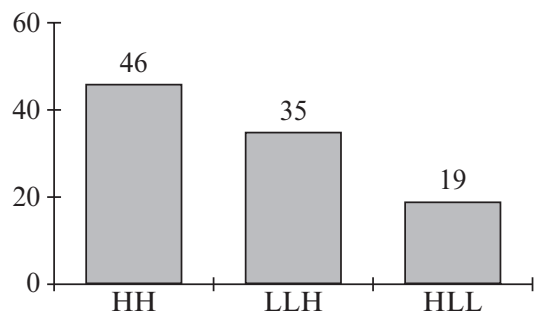

Euripides

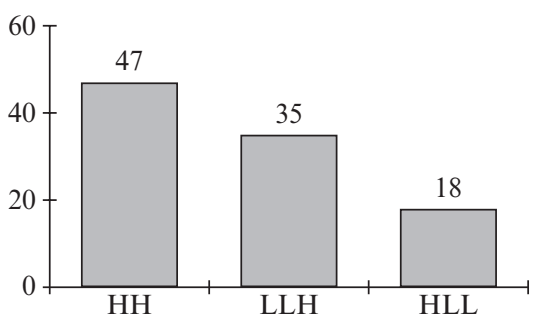


Sophocles

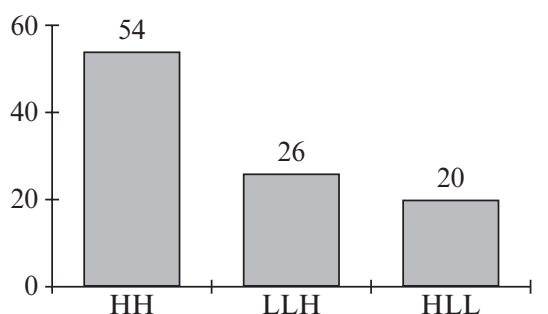

Aristophanes

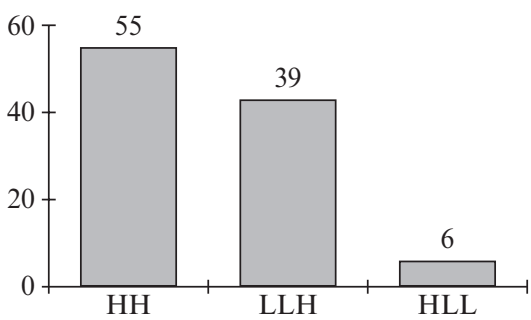

Given a traditional analysis of this meter in which the basic verse foot is a true anapest (LLH), it should come as an unpleasant surprise that only a third of all anapestic verse feet have this shape while fully half run $\mathrm{HH}$ (spondee). We should not infer from this, however, that the meter is REALLY spondaic; rather, we should infer from this that the meter has no inherent rhythm at the syllable level and that the various verse feet are just different ways of having two bimoraic feet in a verse foot.

In order to explain the preference for $\mathrm{HH}$ over other realizations we follow recent work in OT metrics and introduce a weaker set of constraints that accounts for preferences among the allowed verse feet (Friedberg 1997; Golston and Riad 1997; Golston 1998; Hayes and MacEachern 1998). We will refer to the former as essential constraints and to the latter as violable constraints and separate them in tableaux with a dark vertical line. To account for the preferences among different types of verse foot in anapestic meter, we invoke the constraint we shall call PROKOSCH (the stress-to-weight principle) and the well-known constraint NOCLASH.

Eduard Prokosch noted the preferences for stressed syllables to be heavy in Germanic (Prokosch 1939; Vennemann 1988; Riad 1992) and this seems to be a universal tendency (Vennemann 1988). NOCLASH is well known from the literature on prosody (Liberman 1975; Liberman and Prince 1977; Selkirk 1984; Nespor and Vogel 1986, 1989; Kager 1993).

\section{(24) PROKOSCH}

Stressed syllables are heavy.

\section{(25) NOCLASH}

Stressed syllables are not adjacent.

As the tableau below shows, all attested verse feet (口) in anapestic meter respect FTBIN- $\mu$, the essential constraint for this type of meter, shown to the left of the dark line. To the right of that line we have the violable constraints, with PROKOSCH ranked above NOCLASH. 
(26) Realizing the anapest

\begin{tabular}{|c||l|l|l|}
\hline anapest & FTBIN- $\mu$ & PROKOSCH & NOCLASH \\
\hline \hline $\begin{array}{c}(\mathrm{H} \mathrm{H}) \\
\mathrm{x} \mathrm{x}\end{array}$ & & & $*$ \\
\hline $\begin{array}{c}(\mathrm{LL} \mathrm{H}) \\
\mathrm{x} \cdot \mathrm{x}\end{array}$ & & $*$ & \\
\hline $\begin{array}{c}(\mathrm{H} \mathrm{LL}) \\
\mathrm{x} \mathrm{x}\end{array}$ & & $*$ & $*$ \\
\hline $\begin{array}{c}(\mathrm{LL} \mathrm{LL}) \\
\mathrm{x} \cdot \mathrm{x} .\end{array}$ & & $* *$ & \\
\hline
\end{tabular}

All four of these feet are possible anapests because they all respect FTBIN- $\mu$, but some of them make better verse feet than others because they are better formed in terms of NOCLASH and PROKOSCH. The relative frequency with which each type of foot occurs is a function of how well it respects PROKOSCH: HH respects it as the most common verse foot; LLH and HLL violate it once each (for each stressed L) and are therefore less common than HH; and LLLL violates it twice (once for each stressed L) and is thus least common. This leaves a tie between LLH and HLL, but this tie is resolved by NOCLASH, which HLL violates (xx.) and LLH respects (x.x). The two incidental constraints thus give us the ranking found in each of the authors in (23): $\mathrm{HH} \gg \mathrm{LLH} \gg \mathrm{HLL} \gg \mathrm{LLLL}$ (where $\gg$ is to be read is more common than').

We should note here that we do not yet have a fully adequate account of the rarity of LLLL verse feet in comedy or their virtual absence in tragedy. Our analysis only allows us to say that they should be less common than the other types (which is true); they are actually pretty marginal, but our framework doesn't allow us to distinguish between rare and really really rare, at least not in a precise way. We hope that future work in this area will provide a fuller answer to this issue.

With the basic facts about anapests under our belts, let us now see how they are strung together in actual meters. We consider two different lengths here, the simple dimeter and the long tetrameter catalectic.

\subsection{Dimeter}

Most of the plays of Sophocles and Euripides end in an anapestic dimeter system, consisting of a number of lines of plain anapestic dimeter followed 
by a single line of the same type. The final chorus of the Medea, above, is typical. Dimeter systems are also used in comedy, where they tend to occur in much longer runs.

Each line of dimeter has four complete verse feet except for the last line, which has three and a half, due to the catalexis. The meter tends to have about four words per line (see below) with a constant trochaic rhythm at the mora level, as we have just seen. The prosodic structure is perfectly binary, with two moras per metrical position, two metrical positions per verse foot, two verse feet per metron, and two metra per line.

\section{Anapestic dimeter}

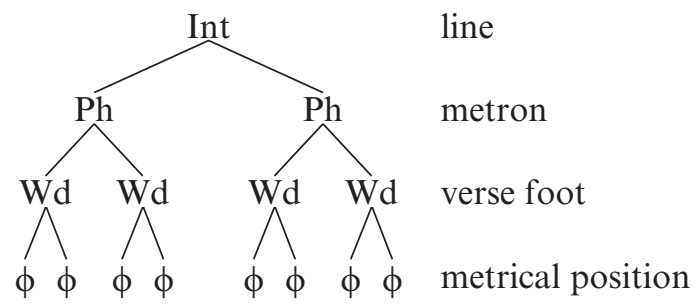

If we are correct in our analysis, the anapestic dimeter is unmarked with respect both to its overall architecture and to its rhythm.

The last line in a dimeter system is one metrical position shorter than the rest. This means that half of one verse foot goes unfilled with text, that is, is catalectic $(\phi-)$.

(28) Anapestic dimeter catalectic

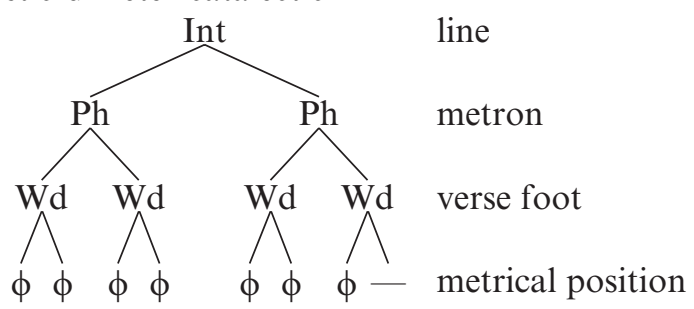

We understand catalexis to be the metrical counterpart of rest in music (Burling 1966). For this reason we treat catalexis as an empty metrical position violating the constraint FILL, which requires prosodic structure to be filled with sounds (Prince and Smolensky 1993: 85). Again, the intuition behind catalexis is that an expected metrical position fails to be realized. We represent this marked state of affairs as distinctive violation of FILL, as we will see in greater detail below.

We have assumed that the verse foot is roughly equivalent to the prosodic word, and we would now like to present evidence for this. 
Although the number of prosodic words is much less consistent than the number of moras in anapestic meter (just as the number of syllables is much less consistent than the number of moras), the average number of words per line is roughly as predicted, 4.4 in our sample. The following chart shows the number of prosodic words for a random selection of dimeter systems in Euripides (Helen 1688-1692; Orestes 1682-1690; Bacchae 1377-1392; Rhesus 1-10, 34-40, 993-996; Alcestis 29-37, 238-243, 273-279, 1159-1163; Medea 143-147, 1081-1115, 1415-1419) and Aristophanes (Frogs 1500-1527).

(29) Number of prosodic words per line of dimeter Euripides Aristophanes
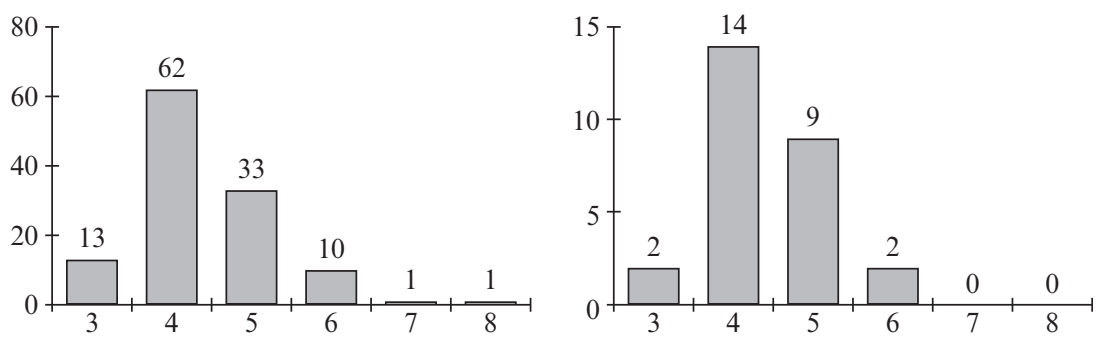

Determining what a prosodic word is in a dead language is not completely straightforward and there are a number of proposals in the literature for Greek. The simplest is probably Golston's (1995) claim that all and only lexical heads form prosodic words in Greek. Devine and Stephens caution against such a simplistic approach, however, arguing that

It is not the case that all nonlexicals have an equal tendency to become appositive; a variety of factors combine to condition the degree to which the rules of word prosody may be extended to phrasal domains in any structure. This is why detailed analysis of the phonology of nonlexicals generally reveals a hierarchy (Devine and Stephens 1994: 330).

To obtain a conservative count of prosodic words we included all words (lexical or not) except for the traditional class of proclitics (Wackernagel 1914; Vendryes 1945; Sommerstein 1973) and enclitics (Postgate 1924; Vendryes 1945), short nonlexical words that tend to surface without the pitch accent associated with other words. Thus in the section from Medea in (11) above, the two words en 'in' in the first line and ouk 'not' in the third were not counted as prosodic words on their own because they are toneless. As can be seen, the resulting ratios are roughly identical for Euripides and Aristophanes, and although the number of words per line 
varies, it hovers around four. We take this as supporting evidence for our analysis.

\subsection{Tetrameter catalectic}

The anapestic tetrameter catalectic is the most common of the anapestic meters. It has 15 metrical positions, each of which must contain a heavy syllable or a sequence of two lights as with any anapestic meter. An example from comic dialogue is as follows.

(30) Knights 773-776 (final catalexis)

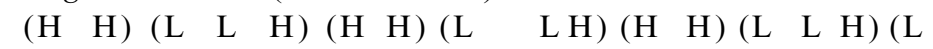
kaì pô:s àn e.móù mâl.lón se $\mathrm{p}^{\mathrm{h}}$ i.lô:n ô: dê:.me gé.noi.to and how prt me more you loving o Demos become $\mathrm{LH})(\mathrm{H}-)$ po.lí:.te:s citizen

$\left(\begin{array}{llll}\mathrm{H} & \mathrm{H}\end{array}\right)(\mathrm{L} \quad \mathrm{L} \quad \mathrm{H})(\mathrm{L} \quad \mathrm{L} \quad \mathrm{H})\left(\begin{array}{ll}\mathrm{H} H & \mathrm{H}\end{array}\right)\left(\begin{array}{lll}\mathrm{H} & \mathrm{H}\end{array}\right)\left(\begin{array}{lll}\mathrm{L} & \mathrm{L} & \mathrm{H}\end{array}\right)$ hòs prô:.ta mén he:ník' e.boú.leu.ón soi $\mathrm{k}^{\mathrm{h}}$ ré:.ma.ta pléist' who first prt when advised ${ }_{1}$ you money much $\left(\begin{array}{lll}\mathrm{L} & \mathrm{L} & \mathrm{H}\end{array}\right)(\mathrm{H}-)$ a.pé.deik.sa accepted

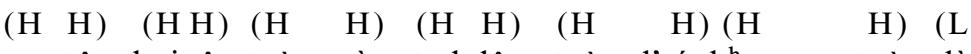
en tô koinô: toùs mèn streb.lô:n toùs $\mathrm{d}^{\prime}$ ánk $\mathrm{k}^{\mathrm{h}} \mathrm{O}: \mathrm{n}$ toùs dè in the public $_{d}$ the $e_{a p}$ prt stretching the $e_{a p} \&$ strangling $_{g p}$ the $e_{a p} \&$ $\mathrm{LH})(\mathrm{H}-)$

metaitô:n begging

$\left(\begin{array}{lllll}\mathrm{H} & \mathrm{H}\end{array}\right)(\mathrm{H} \quad \mathrm{H}) \quad\left(\begin{array}{lllll}\mathrm{H} & \mathrm{LL}\end{array}\right)(\mathrm{HH}) \quad\left(\begin{array}{lll}\mathrm{H} & \mathrm{L} & \mathrm{L}\end{array}\right)\left(\begin{array}{lll}\mathrm{H} & \mathrm{H}\end{array}\right)$

ou $\mathrm{p}^{\mathrm{h}}$ ron.tíz.do:n tô:n i.di.o:.tô:n ou.de.nó.s ei soì not noticing the private $_{g p}$ none $_{g}$ if $y u_{d}$ $(\mathrm{L} \mathrm{LH})(\mathrm{H}-)$ $\mathrm{k}^{\mathrm{h}}$ a.ri.oí.me:n please $_{1 \mathrm{pl}}$ 'And how could anyone come to love you more than I do, you who took in so much money when I first started to help you out,

squeezing and strangling favors from some in public, begging from others,

Not caring how any of the private citizens did as long as I pleased you?' 
As we have said, it is hard to know exactly which metrical position is the catalectic one, so we follow traditional analyses and assume it is the last, since catalexis (like extrametricality) seems to target final constituents rather than initial ones, at least in phonology (Kiparsky 1991).

Quite a lot hinges on this, however, and we do not pretend that the matter has been decided. For one thing, the clearest case of catalexis in Greek stichic meter, iambic tetrameter catalectic, has initial catalexis, not final (see below). Burling (1966) shows that both initial and final catalexis can be found in children's meter cross-linguistically, and classicists assume both initial and final catalexis in analyzing various Greek meters. Indeed, the very idea that this meter is anapestic comes from the claim that the seventh foot is almost always LLH in comedy. The problem of course is that if the catalexis is initial, the seventh foot is regularly HLL, as shown below. ${ }^{8}$

(31) Knights 773-776 (assuming that catalexis is initial)

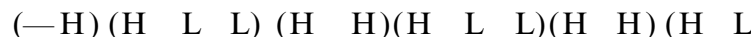

kaì pô:s àn e.móù mâl.lón se $\mathrm{p}^{\mathrm{h}}$ i.lô:n ô: dê:me

L) $\left(\begin{array}{ll}\mathrm{H} \mathrm{L} & \mathrm{L}\end{array}\right)(\mathrm{HH})$

gé.noi.to po.lí:.te:s

$(-\mathrm{H})\left(\begin{array}{lll}\mathrm{H} & \mathrm{L} & \mathrm{L}\end{array}\right)\left(\begin{array}{lll}\mathrm{H} & \mathrm{L} & \mathrm{L}\end{array}\right)\left(\begin{array}{ll}\mathrm{H} & \mathrm{H}\end{array}\right)\left(\begin{array}{ll}\mathrm{H} & \mathrm{H}\end{array}\right) \quad\left(\begin{array}{lll}\mathrm{H} & \mathrm{L} \mathrm{L}\end{array}\right)$

hòs prô:.ta mén he:.ník' e.boú.leu.ón soi $\mathrm{k}^{\mathrm{h}}$ ré:.ma.ta

$\left(\begin{array}{lll}\mathrm{H} & \mathrm{L} & \mathrm{L}\end{array}\right)(\mathrm{H} \quad \mathrm{H})$

pléìst' a.pé.deik.sa

$\left(\begin{array}{ll}-\mathrm{H} \\ )(\mathrm{H} & \mathrm{H}\end{array}\right)\left(\begin{array}{ll}\mathrm{H} & \mathrm{H}\end{array}\right)\left(\begin{array}{lll}\mathrm{H} & \mathrm{H}\end{array}\right)\left(\begin{array}{lll}\mathrm{H} & \mathrm{H}\end{array}\right) \quad\left(\begin{array}{ll}\mathrm{H} & \mathrm{H}\end{array}\right)$

en tô: koinô: toùs men streb.lô:n toùs d' ánk $\mathrm{k}^{\mathrm{h}}: \mathrm{n}$

$\left(\begin{array}{lll}\mathrm{H} & \mathrm{L} & \mathrm{L}\end{array}\right)(\mathrm{HH})$

toùs dè metaitô:n

$\left(\begin{array}{lll}-\mathrm{H}) & (\mathrm{H} & \mathrm{H}\end{array}\right)\left(\begin{array}{ll}\mathrm{H} & \mathrm{H}\end{array}\right)(\mathrm{L} \mathrm{LH})\left(\begin{array}{lll}\mathrm{H} & \mathrm{H}\end{array}\right)\left(\begin{array}{lll}\mathrm{L} & \mathrm{L} & \mathrm{H}\end{array}\right)$

ou $\mathrm{p}^{\mathrm{h}}$ ron.tíz.do:n tô:n i.di.o:tô:n ou.de.nó.s ei

( $\left.\begin{array}{ll}\mathrm{H} & \mathrm{L} \\ \mathrm{L}\end{array}\right)(\mathrm{H} \mathrm{H})$

soì $\mathrm{k}^{\mathrm{h}}$ a.ri.oí.me:n

This is not an issue we can answer here - we know of no conclusive evidence (from bridges, caesurae, etc.) that catalexis in this meter is either initial or final. ${ }^{9}$ But we should not assume that the seventh foot is always LLH any more than we should assume that it is always HLL. We simply don't know at this point whether the catalectic position is line-initial or line-final. 
With that in mind we can sketch the meter at hand as follows.

(32) Anapestic tetrameter catalectic

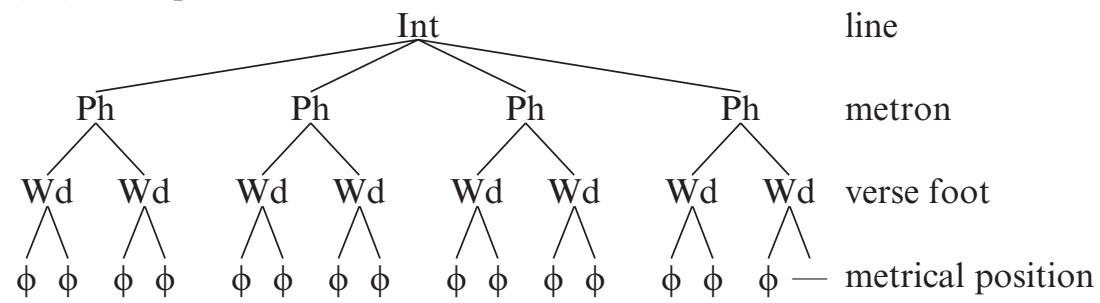

Comparing this meter with the dimeter discussed above (27) we see that the only differences are that the tetrameter has four daughters (tetrameter) instead of two and that the final verse foot is half-empty (catalexis).

The tetrameter part of this can be treated as violating the constraint INTBIN, which requires that lines (intonational phrases) be binary, not ternary or quaternary or the like. ${ }^{10}$ If the unmarked case is to have an intonational phrase branch once (dimeter), then having it branch twice should violate INTBIN once and having it branch three times should violate INTBIN twice.

\subsection{Markedness}

We want to show that distinctive violation of constraints is the simplest way of defining meters. The idea is that the poet intentionally violates a prosodic constraint to achieve some kind of noticeable structural or rhythmic effect. In the cases at hand we need to define what it is to be anapestic dimeter, anapestic dimeter catalectic, and anapestic tetrameter catalectic.

Anapestic dimeter we take to be completely unmarked in terms of both rhythm and length. We repeat its structure below for convenience.

(33) Anapestic dimeter

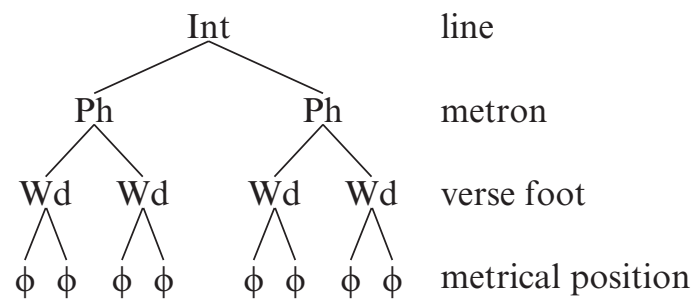


Since it doesn't violate any constraints on binarity or on rhythm, there isn't a lot to say about it in terms of markedness. We can say that it ranks binarity and rhythm very highly, even above morphosyntactic concerns, but this is not something peculiar to this meter. So we will leave the unmarked meter unmarked.

Moving on to the catalectic version of anapestic dimeter that we find at the end of most dimeter systems, we note that it has one less filled metrical position than we expect a dimeter to have.

\section{Anapestic dimeter catalectic}

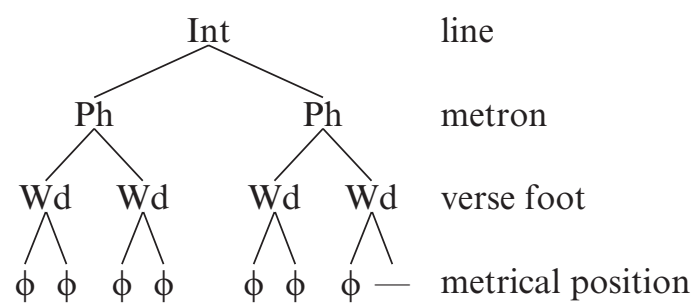

Again, most of the structure and rhythm is unmarked, so we are left with little to notate overtly except the catalexis. We capture this formally by noting that a catalectic meter intentionally violates FILL.

$$
\begin{aligned}
& \text { Catalexis } \\
& \begin{array}{|c|}
\hline \text { FILL } \\
\hline \hline \text { C }
\end{array}
\end{aligned}
$$

The formalism is to be read 'a line is catalectic (C) if it violates the constraint FILL'. We could of course find some other way of making the line violate FILL and then note that the line does violate FILL, but the point of using markedness in grammatical description is precisely to avoid this type of indirectness (Golston 1996). Unless the catalexis we find regularly is demonstrably the byproduct of something else, we can simply note the markedness of the situation with a constraint violation. Put less formally, if someone respects binarity and moraic rhythm but violates FILL, she is speaking anapestic dimeter catalectic.

Anapestic tetrameter catalectic is still rhythmically unmarked, but it now has two peculiarities in terms of length: it is twice as long as we would expect it to be (if it were a dimeter) and it has one less metrical position than we'd expect it to have (binary meters always have an even number of metrical positions). 
(36) Anapestic tetrameter catalectic

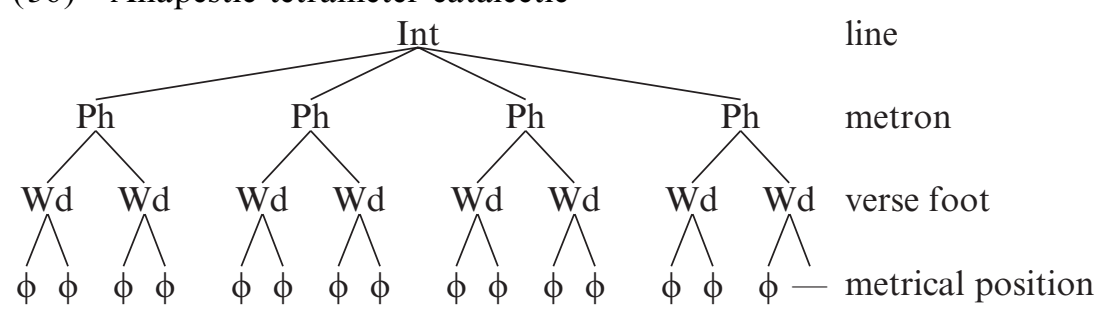

The length part comes about because the line has four daughters (tetrameter) instead of two (dimeter), that is, because it branches three times instead of just once. We can register this in terms of markedness as a double violation of INTBIN, the requirement that intonational phrases (lines) branch once.

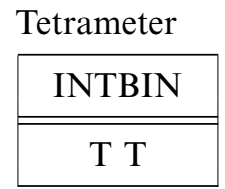

The formalism reads 'a line (intonational phrase) is a tetrameter if it branches two times more than normal'. The marked parts of anapestic tetrameter catalectic are thus just being catalectic, (35), and being a tetrameter, (37), which are enough to distinguish a catalectic tetrameter from the unmarked dimeter.

Turning back to the anapestic part of the meter, let us see precisely how the constraints we have invoked describe the structures we find. Recall that there are four distinct ways to realize an anapestic verse foot in Greek meter: HH, LLH, HLL, and LLLL, in descending order of preference. These represent all and only the strings that consist of exactly two bimoraic trochees. Two binarity constraints (WDBIN and FTBIN- $\mu$ ) ensure this, as we can see in the tableau below, where actual verse feet (a) are compared with a few nonoccurring ones. 
(38) The anapestic verse foot

\begin{tabular}{|c||c|c|}
\hline & WDBIN & FTBIN- $\mu$ \\
\hline \hline$(\mathrm{H} \mathrm{H})$ & & \\
\hline & & \\
\hline$(\mathrm{H} \mathrm{LL})$ & & \\
\hline$(\mathrm{LL} \mathrm{H})$ & & \\
\hline$(\mathrm{LL} \mathrm{H})$ & & $* !$ \\
\hline$(\mathrm{L} \mathrm{L})$ & & $* !$ \\
\hline$(\mathrm{H} \mathrm{LL} \mathrm{H})$ & $* !$ & \\
\hline$(\mathrm{H} \mathrm{H} \mathrm{H})$ & $* !$ & \\
\hline
\end{tabular}

The first two losing candidates lose because they contain degenerate feet $(\mathrm{L})$, in violation of FTBIN- $\mu$, an essential constraint in this meter; the last two candidates (and many more imaginable ones) lose because they branch twice, in fatal violation of WDBIN, another essential constraint in Greek anapestic meter.

We have defined the natural class of verse feet in anapestic meter as just those verse feet that respect both WDBIN (two metrical positions per verse foot) and FTBIN- $\mu$ (two moras per metrical position). Going up one level in the metrical hierarchy, we see that the class of metra in anapestic meter includes all and only those 16 metra that respect PHBIN, WDBIN, and FTBIN- $\mu$. 
(39) The anapestic metron

\begin{tabular}{|c|c|c|c|}
\hline & PHBIN & WDBIN & FTBIN- $\mu$ \\
\hline 蛏 $)(\mathrm{H} \mathrm{H})$ & & & \\
\hline$(\mathrm{H} \mathrm{H})(\mathrm{H} \mathrm{LL})$ & & & \\
\hline$(\mathrm{H} \mathrm{H})(\mathrm{LL} \mathrm{H})$ & & & \\
\hline$(\mathrm{H} \mathrm{H})(\mathrm{LL} \mathrm{LL})$ & & & \\
\hline (H LL) $(\mathrm{H} \mathrm{H})$ & & & \\
\hline (H LL) (H LL) & & & \\
\hline$(\mathrm{H} \mathrm{LL})(\mathrm{LL} \mathrm{H})$ & & & \\
\hline$(\mathrm{H}$ LL) (LL LL) & & & \\
\hline$(\mathrm{LL} \mathrm{H})(\mathrm{H} \mathrm{H})$ & & & \\
\hline$(\mathrm{LL} \mathrm{H})(\mathrm{H} \mathrm{LL})$ & & & \\
\hline$(\mathrm{LL} \mathrm{H})(\mathrm{LL} \mathrm{H})$ & & & \\
\hline$(\mathrm{LL} \mathrm{H})(\mathrm{LL} \mathrm{LL})$ & & & \\
\hline$(\mathrm{LL} \mathrm{LL})(\mathrm{H} \mathrm{H})$ & & & \\
\hline (LL LL) (H LL) & & & \\
\hline$($ LL LL) $($ LL H $)$ & & & \\
\hline (LL LL) (LL LL) & & & \\
\hline$(\mathrm{L} \mathrm{H})(\mathrm{H} \mathrm{H})$ & & & $* !$ \\
\hline$(\mathrm{H} \mathrm{L} \mathrm{H})(\mathrm{LL} \mathrm{LL})$ & & $* !$ & \\
\hline$(\mathrm{H} \mathrm{H})(\mathrm{H} \mathrm{LL})(\mathrm{H} \mathrm{H})$ & $* !$ & & \\
\hline
\end{tabular}

A tableau for an entire line of anapestic dimeter would include 256 $(16 \times 16)$ distinct winning line types.

The distinctive violation of FILL in a catalectic meter occurs in the evaluation of full lines. Below we compare three lengths of anapestic meter on the grammar of anapestic tetrameter catalectic (recall that ' $\mathrm{C}$ ' marks catalexis). 
(40) Anapestic tetrameter catalectic

\begin{tabular}{|c|c||l|l|}
\hline & & PHBIN & FILL \\
\hline \hline a. & $\begin{array}{l}\text { (LL H) (LL LL) (H H) } \\
(\mathrm{LL} \mathrm{H})(\mathrm{LL} \mathrm{H})(\mathrm{H} \mathrm{LL}) \\
(\mathrm{LL} \mathrm{H})(\mathrm{LL} \mathrm{H})\end{array}$ & & $<\mathrm{C}>$ ! \\
\hline b. & $\begin{array}{l}(-\mathrm{H})(\mathrm{LL} \mathrm{LL})(\mathrm{H} \mathrm{H}) \\
(\mathrm{LL} \mathrm{H})(\mathrm{LL} \mathrm{H})(\mathrm{H} \mathrm{LL}) \\
(\mathrm{LL} \mathrm{H})(\mathrm{H}-)\end{array}$ & & $\mathrm{C} * !$ \\
\hline c. $\rightarrow$ & $\begin{array}{l}\text { (LL H) }(\mathrm{LL} \mathrm{LL})(\mathrm{H} \mathrm{H}) \\
(\mathrm{LL} \mathrm{H})(\mathrm{LL} \mathrm{H})(\mathrm{H} \mathrm{LL}) \\
(\mathrm{LL} \mathrm{H})(\mathrm{H}-)\end{array}$ & & \\
\hline
\end{tabular}

Candidate (a) is acatalectic, that is, the distinctive violation of FILL is lacking because all of the metrical positions have text in them. This line is essentially better than it is supposed to be. A catalectic line is supposed to have an unfilled metrical position and candidate (a) does not. Candidate (b) has the required violation (-) but also one more at the beginning of the line. That is one too many; a catalectic line is supposed to have only one unfilled metrical position. Finally, candidate (c) has exactly one unfilled metrical position, as called for, and is therefore a well-formed line in this type of meter.

A constraint-based approach like this entirely avoids the need for metrical templates. The result looks as if text were matched to an abstract template but this is brought about not by a matching procedure but simply by respecting (or violating) specific constraints on binarity and faithfulness. Once we know how much of the structure is marked, we know how much of the prosodic structure must be unmarked; and these two bits of information are enough to rule out ill-formed lines and to rule in acceptable ones.

As we now move on to the other spoken meters of Greek, we should keep the anapest in mind. Anapestic meter is rhythmically unmarked, most of its character flowing directly from unviolated constraints on binarity from the mora to the utterance. The other meters we will consider dactylic, iambic, spondaic - are all rhythmically marked and it is their rhythmic markedness that sets them apart from the anapests.

\section{Dactylic hexameter}

The works of Homer (Iliad, Odyssey), Hesiod (Theognis, Works and Days), and others were written in a meter with six HLL or HH verse feet per line. Consider the first few lines of the Iliad. 
(41) Homer, Iliad A 1-7

$\left(\begin{array}{llll}H & L & L\end{array}\right)(\mathrm{HL} \quad \mathrm{L})(\mathrm{H} \quad \mathrm{H})(\mathrm{H} \mathrm{LL})(\mathrm{H} \quad \mathrm{L} \quad \mathrm{L})(\mathrm{H} \mathrm{H})$

mê:.nin á.ei.de, $\mathrm{t}^{\mathrm{h}}$ eá:, pe:.le:.i.á.deo: a.k $\mathrm{k}^{\mathrm{h} i . l e ̂}: . o s$

anger sing goddess Pelian ${ }_{\mathrm{g}} \quad$ Achilles $_{\mathrm{g}}$

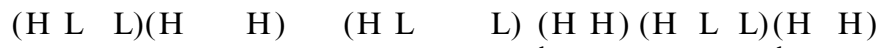

ou.lo.mé.ne:n, hè: mu.rí a.k ${ }^{\mathrm{h} a i . o ́ i s ~ a ́ l . g e ' ~ e ́ . ~} \mathrm{t}^{\mathrm{h}} \mathrm{e} . \mathrm{ke}$

devastation which thousands Achaians pains put

$\left.\left(\begin{array}{lll}\mathrm{H} \mathrm{H} & (\mathrm{H} & \mathrm{H}\end{array}\right) \quad \mathrm{H}\right)\left(\begin{array}{lll}\mathrm{H} & \mathrm{LL}\end{array}\right)\left(\begin{array}{lll}\mathrm{H} & \mathrm{LL}\end{array}\right)\left(\begin{array}{ll}\mathrm{H} & \mathrm{H}\end{array}\right)$

pol.làs d'ip ${ }^{\mathrm{h}} . \mathrm{t}^{\mathrm{h}} 1$ i.:mous psu:.. $\mathrm{k}^{\mathrm{h}}$ à:s á.i.di: pro.f.ap.sen

many \& strong souls Hades forth-sent

$\left(\begin{array}{ll}\mathrm{H} & \mathrm{H}\end{array}\right)\left(\begin{array}{ll}\mathrm{H} & \mathrm{H}\end{array}\right)\left(\begin{array}{lll}\mathrm{H} & \mathrm{L} & \mathrm{L}\end{array}\right)(\mathrm{H} \quad \mathrm{LL})\left(\begin{array}{lll}\mathrm{H} & \mathrm{L} & \mathrm{L}\end{array}\right)\left(\begin{array}{ll}\mathrm{H} & \mathrm{H}\end{array}\right)$

he:.ró:.o:n, au.toùs dè he.ló:.ri.a téu. $\mathrm{k}^{\mathrm{h}} \mathrm{e}$ kú.nes.sin

heroes $_{\mathrm{g}}$ them \& spoils gave dogs

$(\mathrm{HH})\left(\begin{array}{lll}\mathrm{H} & \mathrm{L} & \mathrm{L}\end{array}\right)\left(\begin{array}{lll}\mathrm{H} & \mathrm{L} & \mathrm{L}\end{array}\right)(\mathrm{H} \quad \mathrm{L} \mathrm{L}(\mathrm{HL} \mathrm{L})(\mathrm{H} \mathrm{H})$

oi.o:nói.sí te pâ:.si, di.òs d' e.te.leí.e.to bou.lé:

birds $_{\mathrm{g}} \quad \&$ all $_{\mathrm{g}}$ god's \& finished will

$\left(\begin{array}{llll}\mathrm{H} & \mathrm{H}\end{array}\right) \quad\left(\begin{array}{llll}\mathrm{H} & \mathrm{H}\end{array}\right)\left(\begin{array}{lll}\mathrm{H} & \mathrm{L} & \mathrm{L}\end{array}\right)(\mathrm{HH})(\mathrm{H} \quad \mathrm{L} L)(\mathrm{HH})$

eks hóù dè: tà prô:.ta di.as.té:.te:n e.rí.san.te

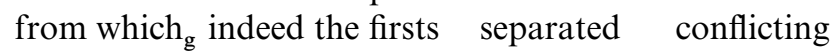

$\left(\begin{array}{ll}\mathrm{H} & \mathrm{LL}\end{array}\right)(\mathrm{H} \quad \mathrm{L} \mathrm{L})(\mathrm{H} \quad \mathrm{H})\left(\begin{array}{lll}\mathrm{H} & \mathrm{H}\end{array}\right)\left(\begin{array}{lll}\mathrm{H} & \mathrm{L} & \mathrm{L}\end{array}\right)\left(\begin{array}{ll}\mathrm{H} & \mathrm{H}\end{array}\right)$

a:.tre.í.de:s te a.naks an.drô:n kaì dî:.os a.k ${ }^{\mathrm{h}}$ il.leús

Atrean \& king men g $_{\mathrm{g}} \quad$ shiny Achilleus

'Sing, goddess, the anger of Peleus' son Achilles,

the devastation that gave endless pain to the Achaians,

and sent so many strong souls down to Hades,

The souls of heroes; but they themselves he gave as spoils to dogs and to all the birds; and the will of Zeus was fulfilled.

From which time these men first parted in conflict,

Atreus' son a king of men and brilliant Achilles.'

The dactylic and hexameter parts are clearly separable and so we must look for phonologically constrained ways to analyze them. We will do both in terms of markedness essentially by showing how different this meter is from the anapestic dimeter in terms of rhythm and binarity.

\section{1. "Dactylic"}

The first task is to characterize HLL and HH as a natural class. Note that it cannot be a characterization based on good rhythm because of the stress 
clash involved in HH (rhythmically $\mathrm{xx}$ at the syllable level). Indeed, when we look a bit deeper and apply what we know of Greek prominence, there is stress clash with HLL as well. If we spell out the prominence relations at the syllable level for the lines above we get the pattern in (42).

(42) Dactylic hexameter

\begin{tabular}{|c|c|c|c|c|c|}
\hline $\begin{array}{ll}x & x \\
H & L\end{array}$ & $\begin{array}{lc}x & x . \\
H & L L)\end{array}$ & $\begin{aligned} \begin{array}{c}\mathrm{X} \\
\mathrm{H}\end{array} & \mathrm{X}\end{aligned}$ & $\begin{array}{c}x \quad x . \\
(H \quad L L)\end{array}$ & 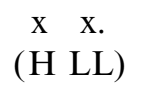 & $\begin{array}{cc}x & X \\
(H & H\end{array}$ \\
\hline $\begin{array}{ll}x & x \\
H & H\end{array}$ & $\begin{array}{c}\mathrm{X} \quad \mathrm{X} \\
(\mathrm{H} H\end{array}$ & $\begin{array}{cc}X & X \\
(H & Y\end{array}$ & $\begin{array}{cc}x & x . \\
(H & L I\end{array}$ & 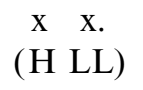 & $\begin{array}{c}\mathrm{X} \\
(\mathrm{H}\end{array}$ \\
\hline $\left.\begin{array}{ll}x & x \\
H & H\end{array}\right)$ & $\begin{array}{cc}x \quad x \\
(H \quad H)\end{array}$ & 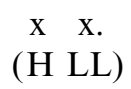 & 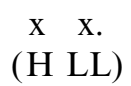 & 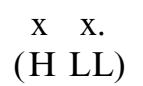 & $\begin{array}{c}\mathrm{X} \\
(\mathrm{H}\end{array}$ \\
\hline $\begin{array}{lc}X & x \\
H & H)\end{array}$ & $\begin{array}{cc}X & x . \\
(H & L L\end{array}$ & $\begin{array}{cc}X & X . \\
(H & L L\end{array}$ & 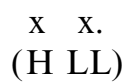 & $\begin{array}{cc}X & X . \\
(H & L L\end{array}$ & $\begin{array}{c}\mathrm{X} \\
(\mathrm{H}\end{array}$ \\
\hline $\begin{array}{ll}x & x \\
H & H\end{array}$ & $\begin{array}{cc}x & x \\
\left(\begin{array}{ll}H & H\end{array}\right)\end{array}$ & 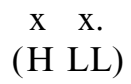 & 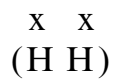 & 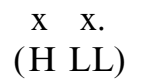 & $\begin{array}{c}\mathrm{X} \\
(\mathrm{H}\end{array}$ \\
\hline $\begin{array}{ll}x & x \\
H & \end{array}$ & $\begin{array}{cc}X & X . \\
(H & L L)\end{array}$ & 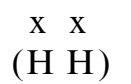 & 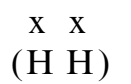 & $\begin{array}{cc}x & x . \\
(H & L L)\end{array}$ & $\begin{array}{c}\mathrm{X} \\
(\mathrm{H}\end{array}$ \\
\hline
\end{tabular}

One rhythmic regularity stands out very clearly: EVERY VERSE FOOT CONTAINS A STRESS CLASH. This is the clearest surface difference between dactylic and anapestic meter. While anapests lack a specific and predictable rhythm, dactyls have a stable, recurring, ARRHYTHMIC property. Stress clash occurs in every verse foot, six times per line in every one of the 28,000 -some lines of the Iliad and Odyssey. This simple observation belies the arrhythmic nature of dactylic hexameter. Relentless stress clash follows necessarily from the nature of the meter (HLL or HH) and the phonological foot of the language (the moraic trochee). This could not have escaped the Greek ear, and we therefore propose that stress clash is not an unintended byproduct of the meter but its defining rhythmic characteristic.

Traditional analysis assumes that dactylic meter is rhythmic and sets out to find its special rhythm, which is supposed to be HLL. It comes up with the peculiar result that only $60 \%$ of the verse feet have the true dactylic meter - the rest are deviant. But we suspect that if Homer had wanted a perfectly rhythmic line, he would not have chosen a meter with absolutely regular stress clash.

We have taken a more surface-near approach. We put the moraic trochees of Greek into the meter and read the result off of the syllabic prominences. The result is anything but rhythmic, but it is COMPLETELY regular. Our analysis uncovers an exceptionless generalization involving 
stress clash. Once we allow that stress clash can be a rhythmic DEVICE (like rest or syncopation in music) its use in meter is understandable. Unlike anapestic meter, then, dactylic hexameter has a distinctive and utterly regular rhythmic anomaly, constant stress clash.

Returning to the possible verse feet in a language with moraic trochees, consider how stress clash immediately lifts out the two verse feet of dactylic hexameter from the larger pool of verse feet.

(43) Dactylic verse feet

\begin{tabular}{|c|c|c|}
\hline$\left(\begin{array}{ll}H & H\end{array}\right)$ & $\left(\begin{array}{ll}H & L\end{array}\right)$ & $\left(\begin{array}{ll}H & L L\end{array}\right)$ \\
\hline$\left(\begin{array}{ll} & H\end{array}\right)$ & $\left(\begin{array}{ll}(\mathrm{L} & \mathrm{L}\end{array}\right)$ & $\left(\begin{array}{ll} & \mathrm{LL}\end{array}\right)$ \\
\hline$(\mathrm{LL} \mathrm{H})$ & $(\mathrm{LL} \mathrm{L})$ & (LL LL) \\
\hline
\end{tabular}

The rhythmic pattern of (LL H) and (LL LL) are (x.x) and (x.x.) in a language with moraic trochees, both perfectly rhythmic; those of (L H) and (L LL) are (.x) and (.x.), also both perfectly rhythmic. None of these four types supplies the reliable violation of NOCLASH that makes dactylic meter what it is - they would be rhythmic feet in an otherwise perfectly ARRHYTHMIC meter. The remaining three unused feet (HL, LL, LL, L) do not contain the required clashes either: (x..), (x.) (x..).

There is no known Greek (or Latin) work that uses only HLL feet, so it will not do to characterize the meter as essentially HLL and only accidentally $\mathrm{HH}$ (the traditional analysis). As the lines above make clear, dactyls (HLL) and spondees (HH) are about equally common in Greek epic. The chart below shows the ratio of spondees to proper dactyls in the first 52 lines of the Iliad.

(44) Verse feet in dactylic hexameter (\%)

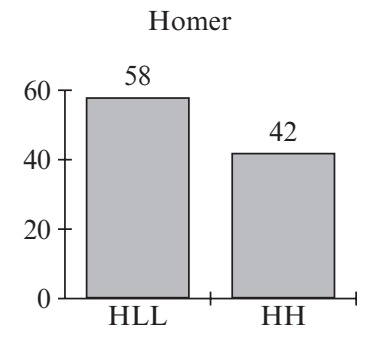

The 60-40 split between HLL and HH is fairly common for Greek (Maas 1962: 59); for Latin haxameter (Ennius, Vergil) the split works in the other direction with more spondees than true dactyls. Indeed, for Ennius the most common type of line is actually $(\mathrm{HH})(\mathrm{HH})(\mathrm{HH})(\mathrm{HH})$ (HLL) (HH). So if we are to call Greek hexameter dactylic because of 
the $60 / 40$ advantage dactyls hold over spondees, we must be willing to call Latin hexameter spondaic because of the 60/40 advantage spondees hold over dactyls. All this would fly in the face of what we know to be true: Latin hexameter was styled directly on Greek hexameter and felt by its practioners to be the same meter. It will not do to define a meter in terms of mere statistical trends. And, as we have seen, there is no need to do so, since there is an exceptionless surface regularity - stress clash that unites every foot of every line of both Greek and Latin hexameter.

We need to account for the statistical differences between Homer and Ennius, but this can be done without abandoning the claim that they wrote in essentially identical meters. For the Greek dactyl we propose a violable constraint that favors disyllabic feet. ${ }^{11}$

(45) FTBIN- $\sigma$

Phonological feet (metrical positions) contain two syllables.

FTBIN- $\sigma$ is not an ad hoc constraint. It is responsible for languages with syllabic trochees rather than moraic trochees (see Hayes 1995 for survey and discussion). Assuming that constraints are universal while their ranking is language-specific (Prince and Smolensky 1993), we rank FTBIN- $\sigma$ well below FTBIN- $\mu$ and allow it only a realizational role in Greek dactylic meter. (In spondaic meter it plays a bigger role; cf. section 5.) Specifically, FTBIN- $\sigma$ makes HLL verse feet better than HH. Assuming that the essential desideratum for dactyls (D) is violation of NOCLASH we may graph the differences between HH and HLL verse feet as follows.

(46) Realizing the dactyl in Greek

\begin{tabular}{|c||l|l|}
\hline dactyl & NOCLASH & FTBIN- $\sigma$ \\
\hline \hline $\begin{array}{c}(\mathrm{H} \mathrm{LL}) \\
\mathrm{x} \mathrm{x}\end{array}$ & $\mathrm{D}$ & \\
\hline $\begin{array}{c}(\mathrm{H} \mathrm{H}) \\
\mathrm{x} \mathrm{x}\end{array}$ & $\mathrm{D}$ & $*$ \\
\hline
\end{tabular}

For the Latin dactyl it is more important that stressed syllables be heavy (Prokosch's law), just as it is in Greek anapestic meter (see [26] above).

(47) Realizing the dactyl in Latin

\begin{tabular}{|c||l|l|}
\hline dactyl & NOCLASH & PROKOSCH \\
\hline \hline $\begin{array}{c}(\mathrm{H} \mathrm{H}) \\
\mathrm{x} \mathrm{x}\end{array}$ & $\mathrm{D}$ & \\
\cline { 2 - 3 } $\begin{array}{c}(\mathrm{H} \mathrm{LL}) \\
\mathrm{x} x\end{array}$ & $\mathrm{D}$ & $*$ \\
\hline
\end{tabular}


Prokosch's law makes HH a better realization in Latin than HLL because $\mathrm{HH}$ has no stressed light syllables, where HLL does (the first of the two Ls).

There is additional evidence that NOCLASH plays a role in hexameter. The relevant fact is that the fifth verse foot is usually HLL - in Homer only one line in 18 has a fifth foot that is HH (Ludwich 1885: 215). We attribute this to the avoidance of stress clash building up at the end of the line. Allen (1973: 107) points out that metrical preferences are felt more keenly toward the end of the line than toward the beginning, citing work on Vedic (Arnold 1905: 9), Classical Arabic (Weil 1960: 669), Finnish (Kiparsky 1968: 138), and Russian (Bailey 1968; 17), to which we might add Modern English (Hayes 1989) and Middle English (Golston 1998). Thus, it makes sense that gratuitous violations of NOCLASH introduced by four heavy line-final syllables would be avoided in hexameter. The final verse foot is always $\mathrm{HH}$, which follows from the fact that the final metrical position is $\mathrm{H}$ in all stichic meter (ANCEPS), and it is likely that this puts pressure on the preceding foot not to end in a $\mathrm{H}$. Consider the first line of the Iliad again, with phrasal prominence building as the line wears on (cf. Hayes 1989 on the meter of Hiawatha).

Homer, Iliad A 1

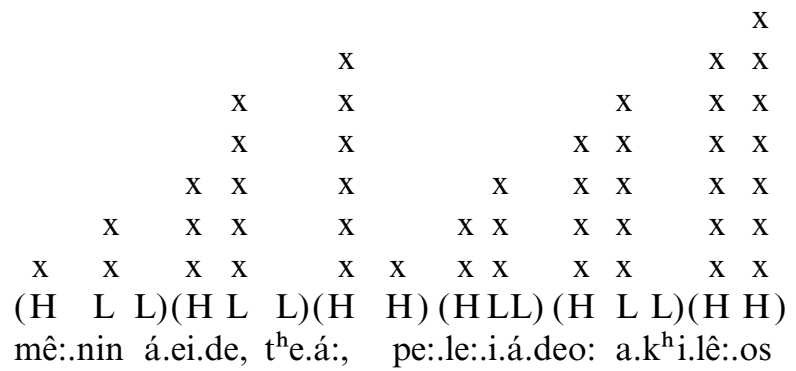

If phrasal stress builds toward the right, the effects of stress clash within and across verse feet should be felt most keenly toward the end of the line, especially if meter regulates this part of the line more strictly than others.

\subsection{Hexameter}

With the dimeter, the unmarked binary nature of prosodic structure yields two metra and four verse feet. Dactylic hexameter has six metra, 
according to traditional analysis, but the number six does not result straightforwardly from binarity.

We assume a fairly traditional structure for the overall architecture of the hexameter, with six verse feet.

(49) Dactylic hexameter

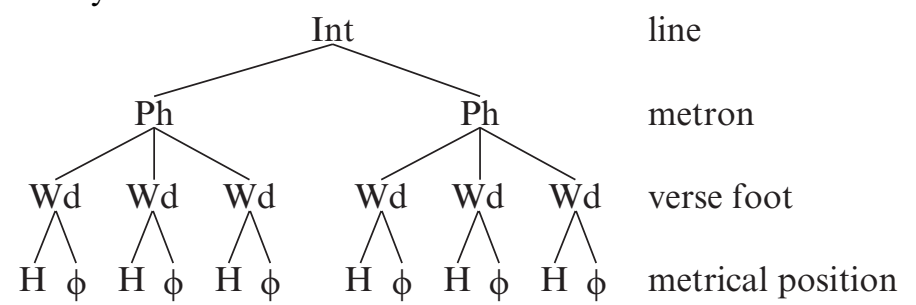

Comparing this tree with the tree for a dimeter in (27) shows that the length of the hexameter comes from the fact that each phonological phrase (metron) branches twice instead of once. Assuming that prosodic structure is supposed to be binary everywhere, the tree above violates this expectation twice at the same level (the metron). Other than that the meter is perfectly binary, with two moras per metrical position, two metrical positions per verse foot, and two metra per line.

Again, the real number of prosodic words in a given line varies somewhat. The following shows the distribution of prosodic words in the first 100 lines of books A and B of the Iliad (counting tonic words only, as discussed above).

(50) Number of prosodic words per line of hexameter

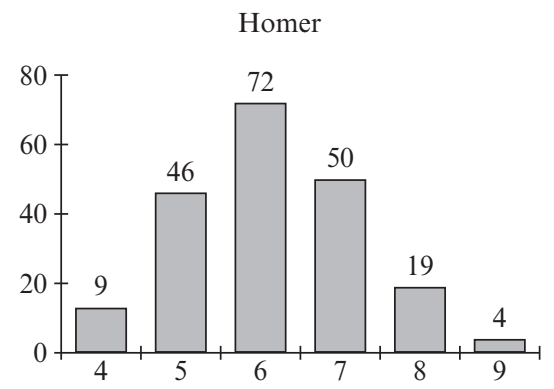

The most common type of line has six prosodic words, the next-most common five or seven, in line with the six-word analysis given here. The average number of words per line in this sample is 6.18 , which we take as supporting our basic analysis. 


\subsection{Markedness}

The only surface true and exceptionless generalization about rhythm in dactylic meter is incessant and completely regular stress clash, something that is found only sporadically in anapestic meters. Thus it seems that the Iliad does not go dum di di (x..); and dum dum (xx) is not somehow an acceptable variant of that basic dactylic rhythm. Rather, dactylic meter runs dum dum di (xx.) or dum dum (xx), with stress clash in every verse foot as the unifying property. The meter is thus rhythmically marked and that makes it what it is. As was hinted at above, we can recognize this marked situation and define dactylic meter as follows.

$$
\begin{aligned}
& \text { Dactylic } \\
& \begin{array}{|c|}
\hline \text { NOCLASH } \\
\hline \hline \text { D } \\
\hline
\end{array}
\end{aligned}
$$

The formalism says that 'a verse foot is a dactyl if it contains a stress clash'.

The defining characteristic in terms of length is that dactyls have two phonological phrases that branch twice instead of the expected once. Assessing one distinctive violation for each additional branch we get the following desiderata for hexameter.

$$
\begin{array}{|c|}
\multicolumn{1}{c}{\text { Hexameter }} \\
\hline \text { PHBIN } \\
\hline \hline \text { H H } \\
\hline
\end{array}
$$

The formalism here is ambiguous between 'a line is a hexameter if it contains a phonological phrase that branches twice more than normal' and 'a line is a hexameter if it contains two phonological phrases that each branch once more than normal' $(=[49])$. The former interpretation would yield a tree like the following (or its reverse with a $4+2$ breakdown).

(53) Alternate form of the hexameter

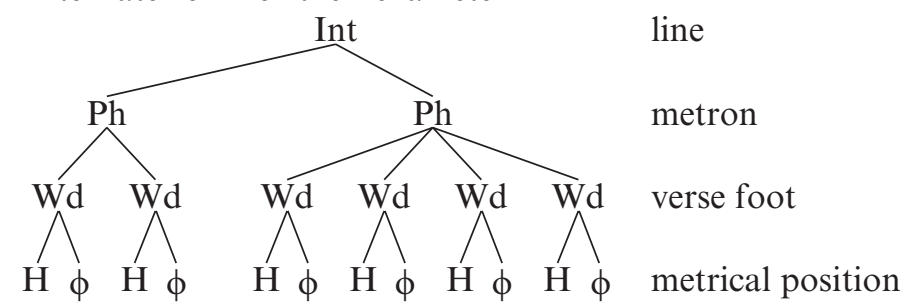


We suspect that this is not the actual structure of dactylic hexameter but are hard pressed to find evidence against it. We will therefore simply assume that prosodic constituents prefer to be divided equally, all things being equal; this would tip the scales in favor of a $3+3$ hexameter.

\section{Iambic meter}

We turn now to iambic meters, which come in two common forms: a simple trimeter and a tetrameter catalectic (also called trochaic tetrameter). Iambic meter is the standard meter of Greek dramatic dialogue, equivalent in that way to the iambic pentameter of Elizabethan drama. Following is a sample of dramatic trimeter, from the beginning of the Medea. The parentheses demarcate metra (PAIRS of verse feet). Thus (HH LH) is two verse feet [HH] and [LH], and (HLL LH) is two verse feet [HLL] and [LH]. This is done to stay in line with traditional analyses, which recognize the basic iambic unit as the metron, not the verse foot.

(54) Euripides' Medea, 1-8

$$
\begin{aligned}
& \left(\begin{array}{llll}
\mathrm{H} & \mathrm{H} & \mathrm{L} & \mathrm{H}
\end{array}\right)\left(\begin{array}{llll}
\mathrm{H} & \mathrm{H} & \mathrm{LH}
\end{array}\right)\left(\begin{array}{llll}
\mathrm{H} & \mathrm{H} & \mathrm{L} & \mathrm{H}
\end{array}\right) \\
& \text { eít }{ }^{\mathrm{h}} \text { ' ó:.phel' Ar.góùs mè: di.ap.tás.t } \mathrm{t}^{\mathrm{h}} \text { ai } \text { ská. }{ }^{\mathrm{h}} \text { os } \\
& \text { if would Argos } \mathrm{g} \text { not through-wing hull }
\end{aligned}
$$

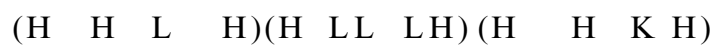

$$
\begin{aligned}
& \text { kól. } \mathrm{k}^{\mathrm{h}} \mathrm{o}: \mathrm{n} \text { es ái.an ku.a.né.as sum.ple:.gá.das } \\
& \text { Colchis into land grey together-clashers } \\
& \left(\begin{array}{llllll}
H & H & \text { L } & H
\end{array}\right)\left(\begin{array}{lllll}
L & H & L & H
\end{array}\right)\left(\begin{array}{llll}
L & H & L & H
\end{array}\right) \\
& \text { me:.d' en ná.pai.si pe:.lí.ou pe.séin po.te } \\
& \text { never in glens } \mathrm{d}_{\mathrm{d}} \text { Pelion }_{\mathrm{g}} \text { fall once } \\
& \left(\begin{array}{llll}
\mathrm{H} & \mathrm{H} & \mathrm{L} & \mathrm{H}
\end{array}\right)\left(\begin{array}{llll}
\mathrm{H} & \mathrm{H} & \mathrm{L} & \mathrm{H}
\end{array}\right)\left(\begin{array}{llll}
\mathrm{H} & \mathrm{H} & \mathrm{L} & \mathrm{H}
\end{array}\right) \\
& \text { tme:.théì.sa peú.ke: me:d' e.ret.mô:.sai k é.ras } \\
& \text { be cut pine nor oars hands }
\end{aligned}
$$

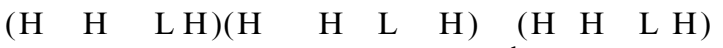

$$
\begin{aligned}
& \text { an.drô:n a.rís.to:n hoì tò páy. } \mathrm{k}^{\mathrm{h}} \text { ru.son dé.ros } \\
& \text { men }_{\mathrm{g}} \text { fine }_{\mathrm{g}} \text { who the all-gold fleece }
\end{aligned}
$$


$\left(\begin{array}{lllllll}\mathrm{L} H & \mathrm{~L} & \mathrm{H}\end{array}\right)\left(\begin{array}{lllll}\mathrm{L} & \mathrm{H} & \mathrm{L} & \mathrm{H}\end{array}\right)\left(\begin{array}{lll}\mathrm{LH} & \mathrm{L} & \mathrm{H}\end{array}\right)$

é.ro:.ti $\mathrm{t}^{\mathrm{h}} \mathrm{u}$ :.mò.n ek.pla.géìs' i.á:.so.nos

love $_{\mathrm{d}}$ heart out-hit Jason $_{\mathrm{g}}$

'Would that the hull of the Argos had not winged

to Colchis through the grey Symplegades!

Would that the pine had never been felled in the glens of

Mt. Pelion

nor been cut into oars for the hands

of fine men who sought out the Golden Fleece

under the command of Pelias,

For then my lady Medea would not

have sailed to the towers of the land of Iolcus

her heart smitten with love for Jason.'

With two verse feet to the metron, iambic trimeter has three metra and six verse feet. As is clear from the sample above, the most striking regularity in the array of $\mathrm{H}$ and $\mathrm{L}$ syllables within the metron is that the third metrical position is always $\mathrm{L}$.

\section{1. "Iambic"}

The commonest verse foot shapes in iambic meter are $\mathrm{LH}$ and $\mathrm{HH}$, as the percentages below (based on Medea 1-8 and Bacchae 616-622) make clear. The sheer number of HH verse feet $(35 \%)$ shows that NOCLASH is not a major consideration for iambic meter, any more than it is for anapestic meter or for prose.

(55) Verse feet in iambic meters $(\%)$

Trimeter

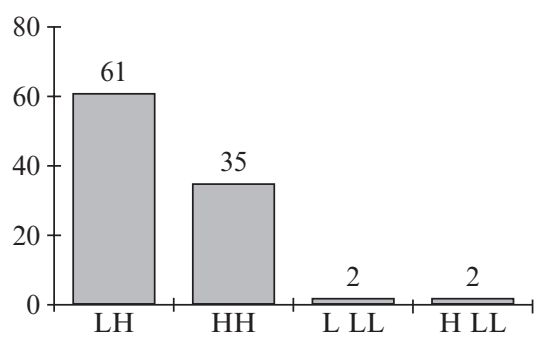

Tetrameter Catalectic

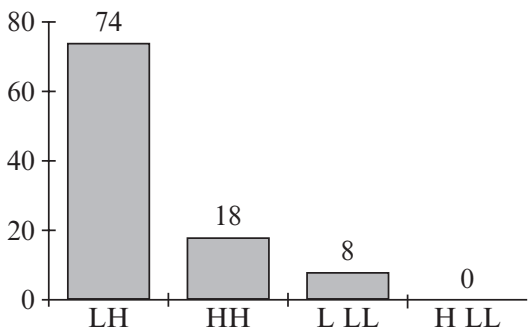

But there is much more to say about iambs in Greek. As we have seen, Greek iambs always come in pairs or metra (as do also iambs in Arabic meters; Golston and Riad 1997). When we look at the various metra, we find that the verse feet $\mathrm{LH}, \mathrm{HH}$, and so on are not evenly distributed throughout the line. 
(56) Metrical positions and iambic metra

$\begin{array}{llll}1 & 2 & 3 & 4 \\ (\mathrm{~L} & \mathrm{H} & \mathrm{L} & \mathrm{H}) \\ (\mathrm{L} & \mathrm{H} & \mathrm{L} & \mathrm{LL}) \\ (\mathrm{L} & \mathrm{LL} & \mathrm{L} & \mathrm{H}) \\ \text { (L } & \text { LL } & \mathrm{L} & \mathrm{LL}) \\ (\mathrm{H} & \mathrm{H} & \mathrm{L} & \mathrm{H}) \\ (\mathrm{H} & \mathrm{H} & \mathrm{L} & \mathrm{LL}) \\ (\mathrm{H} & \mathrm{LL} & \mathrm{L} & \mathrm{H}) \\ (\mathrm{H} & \mathrm{LL} & \mathrm{L} & \mathrm{LL})\end{array}$

Three constant properties stand out clearly:

i. The third metrical position is always light (L).

ii. The second and fourth metrical positions are always bimoraic $(\mathrm{H}$ or LL).

iii. The first metrical position is always a syllable ( $\mathrm{H}$ or $\mathrm{L})$.

How may we account for this? Let's start with (i) and (ii) and notice that the third metrical position is always a light syllable between two bimoraic feet, what Mester (1994) calls a trapped light syllable. Factoring in moraic prominences gives us two feet with a stressless mora in between. Using ' $\mathrm{x}$ ' for a prominent mora and '.' for a nonprominent mora we can schematize this as (x.) . (x.). This is the pattern of prominence we find across the second and third metrical positions of absolutely every metron, as shown below, where we have replaced L with '.', and H and LL with 'x.'.

(57) Moraic prominences in iambic metra

\begin{tabular}{|c|c|c|c|c|}
\hline 2 & 34 & 1 & 2 & \\
\hline $\mathrm{H}$ & $\begin{array}{ll}\mathrm{L} & \mathrm{H}\end{array}$ & (. & $\mathrm{x}$. & \\
\hline $\mathrm{H}$ & L LL) & (. & $\mathrm{x}$. & \\
\hline LL & $\left.\begin{array}{ll}\mathrm{L} & \mathrm{H}\end{array}\right)$ & (. & $\mathrm{x}$. & \\
\hline LL & LL) & (. & $\mathrm{x}$. & \\
\hline $\mathrm{H}$ & H) & (x. & $\mathrm{x}$. & \\
\hline $\mathrm{H}$ & LL) & (x. & $\mathrm{x}$. & \\
\hline LL & H) & (x. & $\mathrm{x}$. & \\
\hline LL & L LL) & & $\mathrm{x}$. & \\
\hline
\end{tabular}

Thus every iambic metron contains exactly one sequence of nonprominent moras, spanning the second and third metrical positions. Kager (1993) calls such a sequence of nonprominent moras a moraic lapse and shows that it is a dispreferred structure in natural languages. This is the only constant, surface-true rhythmic feature of iambic meter in Greek. We therefore treat it as the defining rhythmic characteristic of the meter.

So why moraic lapse instead of plain syllabic lapse? In a language with moraic trochees, heavy syllables $(\mathrm{H})$ are always stressed and the first of 
a pair of light syllables (LL) is stressed as well. When a single L syllable follows, we get HL and LLL. The notion of a syllabic lapse covers only the latter configuration, where the two last light syllables are both unstressed (LLL). Greek metrics does not, however, make this distinction between HL and LLL. Therefore, it is not a lapse at the syllabic level that is relevant, but the lapse at the moraic level, where HL and LLL are rhythmically equal, that is, (x..). Thus, the only type of lapse consistent with the basically similar patterning of $\mathrm{H}$ and $\mathrm{LL}$ one gets in a language like Greek is a pair of adjacent stressless moras. This is a direct consequence of the quantitative basis for rhythm that the moraic trochee can provide, when word stress or tone accent is set aside (as it is in Greek meter). The constraint that iambic meter consistently violates may therefore be given simply as NOLAPSE.

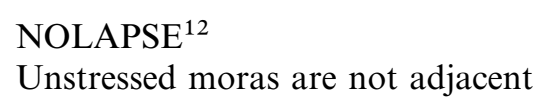

Note that anapestic and dactylic meters never give rise to violations of NOLAPSE, because they both begin and end in bimoraic - and therefore lapseless - sequences. Their moraic prominence always reads (x.x.), whether (HH), (HLL), (LLH), or (LLLL). This is equally true, obviously, of any pair of these verse feet. Thus the iambic arrhythmy we have uncovered not only defines every iambic metron, it also distinguishes those metra from the anapestic and dactylic metra discussed earlier.

We have yet to discuss the third of our three properties of iambic meter, namely that the first metrical position is always a syllable $(\mathrm{H}$ or $\mathrm{L})$. This turns out to be true only for iambic metra that are noninitial; line-initial metra can begin with LL as well. Thus there seems to be a violable constraint at play here whose effects are felt more strongly as one progresses in the line (like NOCLASH in dactylic hexameter). To capture this we again call on PROKOSCH. Recall that PROKOSCH bans stressed light syllables. In the most common types of iambic metron, (HH LH) and ( $\mathrm{LH} \mathrm{LH})$, there are no stressed lights because no light syllable precedes another light with which it could be footed (all light syllables are trapped). In the less-common types of iambic metron, such as line-initial (LLH LH), we get a stressed light syllable again, in violation of PROKOSCH.

If this is the right analysis of line-initial violations of PROKOSCH, we should find the constraint at work elsewhere in the meter as well. And we do. Metra containing LL are fairly rare compared to metra containing $\mathrm{H}$ in the corresponding positions. Consider the commonness of various metra in Aeschylus (Prometheus Bound 1-50), Sophocles (Oedipus Rex 1-50), and Euripides (Helen 1-50), where the category "other" always has a LL sequence in first, second, or fourth position. 
(59) Metra in iambic meters (\%) Aeschylus
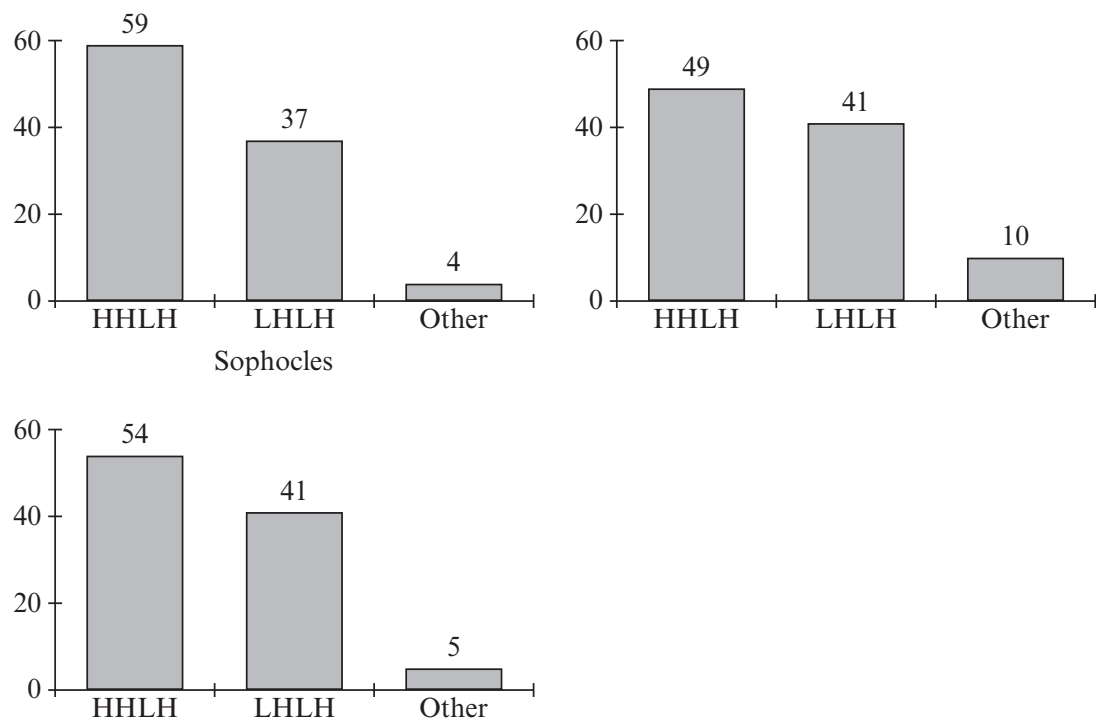

Constraints familiar from earlier discussion rank the different types of metron in terms of frequency.

(60) Realizing the iamb

\begin{tabular}{|c|c|c|c|c|}
\hline metron & NOLAPSE & PROKOSCH & FTBIN- $\mu$ & NOCLASH \\
\hline $\begin{array}{c}(\mathrm{HH} \text { LH }) \\
\mathrm{x} . \mathrm{x} . \mathrm{x} .\end{array}$ & I & & $*$ & * \\
\hline $\begin{array}{c}(\text { LH LH }) \\
\quad . \quad \text {.. x. }\end{array}$ & I & & $* *$ & \\
\hline $\begin{array}{c}(\text { LLH LH }) \\
x . x \ldots x .\end{array}$ & I & $*$ & $*$ & \\
\hline $\begin{array}{c}(\text { HLL LH }) \\
x . x \ldots x\end{array}$ & I & $*$ & $*$ & * \\
\hline $\begin{array}{c}(H \quad H \quad L \quad L L) \\
x . x . . x\end{array}$ & I & $*$ & $*$ & $*$ \\
\hline $\begin{array}{c}(\mathrm{L} \text { LL LH }) \\
. \mathrm{x} \ldots \mathrm{x} .\end{array}$ & I & $*$ & $* *$ & \\
\hline $\begin{array}{c}(\mathrm{L} H \mathrm{H} \text { LL }) \\
\times \ldots \mathrm{X}\end{array}$ & I & $*$ & $* *$ & \\
\hline
\end{tabular}


The two best types of metron (HH.LH and LH.LH) respect PROKOSCH because they have no stressed light syllables. The remaining metra above violate PROKOSCH. One generally finds more metra shaped (HH.LH) than (LH.LH), something we attribute to FTBIN- $\mu$, which (HH.LH) respects more than does (LH.LH).

With the exception of FTBIN- $\mu$, the violable constraints we use here are the same as those used for anapestic meter, and they should be. The data are taken from the same dialect group (Attic) and are roughly synchronic, a few centuries after the composition of the dactylic data from Homer. FTBIN $-\mu$ is a violable constraint here but an essential constraint in anapestic meter. We assume that its natural place in (Attic) Greek is between PROKOSCH and NOCLASH; in anapestic meter it is pulled out and ranked above the syntax as an essential constraint for the meter.

One aspect of our analysis still remains unexplained. Why does it take two verse feet to realize a moraic lapse? Why not have a single verse foot HL realize the lapse (x...)? We do not know the answer to these questions and will only point to where we hope to find an answer. All of the spoken meters in Greek have verse feet that end in a bimoraic sequence $\mathrm{H}$ or LL, as we mentioned at the outset of this paper. We do not know why this is so, but we would like to use this observation to shed some light on the problem at hand. If there is a general constraint that requires verse feet (prosodic words) to end in a moraic trochee, that constraint would rule out the possibility of HL verse; the only way to realize a lapse would then be across verse feet, just as we find in the anapestic metron. We will not pursue the matter further here and hope to return to it in future research. This is a general problem in Greek metrics, not one specific to our proposal.

\section{2. "Trimeter"}

A line of trimeter contains six verse feet organized by pairs into metra; these three metra give the meter its traditional designation as a trimeter. ${ }^{13}$ The six feet are thus organized in a substantially different way than the six feet of hexameter are. To get the three metra we posit the following fairly traditional structure. 
(61) Iambic trimeter

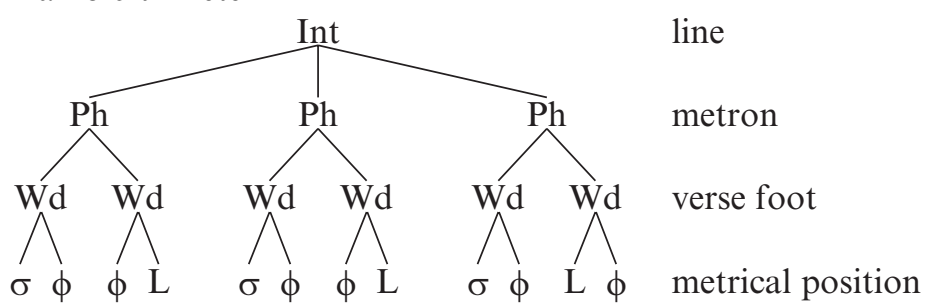

The only thing marked about the tree above is that the line branches twice instead of once as it does in the dimeter; other than that, each metron and verse foot branches exactly once.

Given this analysis of trimeter we expect to find about six words per line, and this is more or less what we find, as a 200-line sample from Euripides shows (Helen 1-100; Phoenicians 1-100).

(62) Number of prosodic words per line of trimeter (\%)

$$
\text { Euripides }
$$

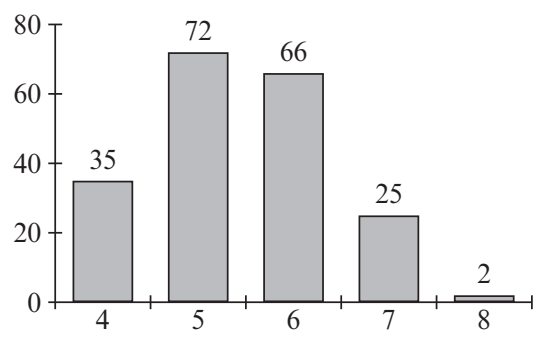

The most common type of line has five prosodic words where we would expect six, but the number of six-word lines is very close and the average number of words per line is 5.45, just under what we would expect given the present analysis. ${ }^{14} \mathrm{We}$ suspect that two things are responsible for the lower number of words in trimeter. First, trimeter has only 18-21 moras per line while hexameter has a full 24 ; second, the final line in dimeter systems is catalectic, further reducing the number of moras available for words.

\subsection{Tetrameter catalectic}

The iambic tetrameter catalectic is thought to have been the original meter of tragic dialogue, later replaced by iambic trimeter (Raven 1962: 34). Consider an example of this meter from the Bacchae. 
(63) Euripides, Bacchae 616-622

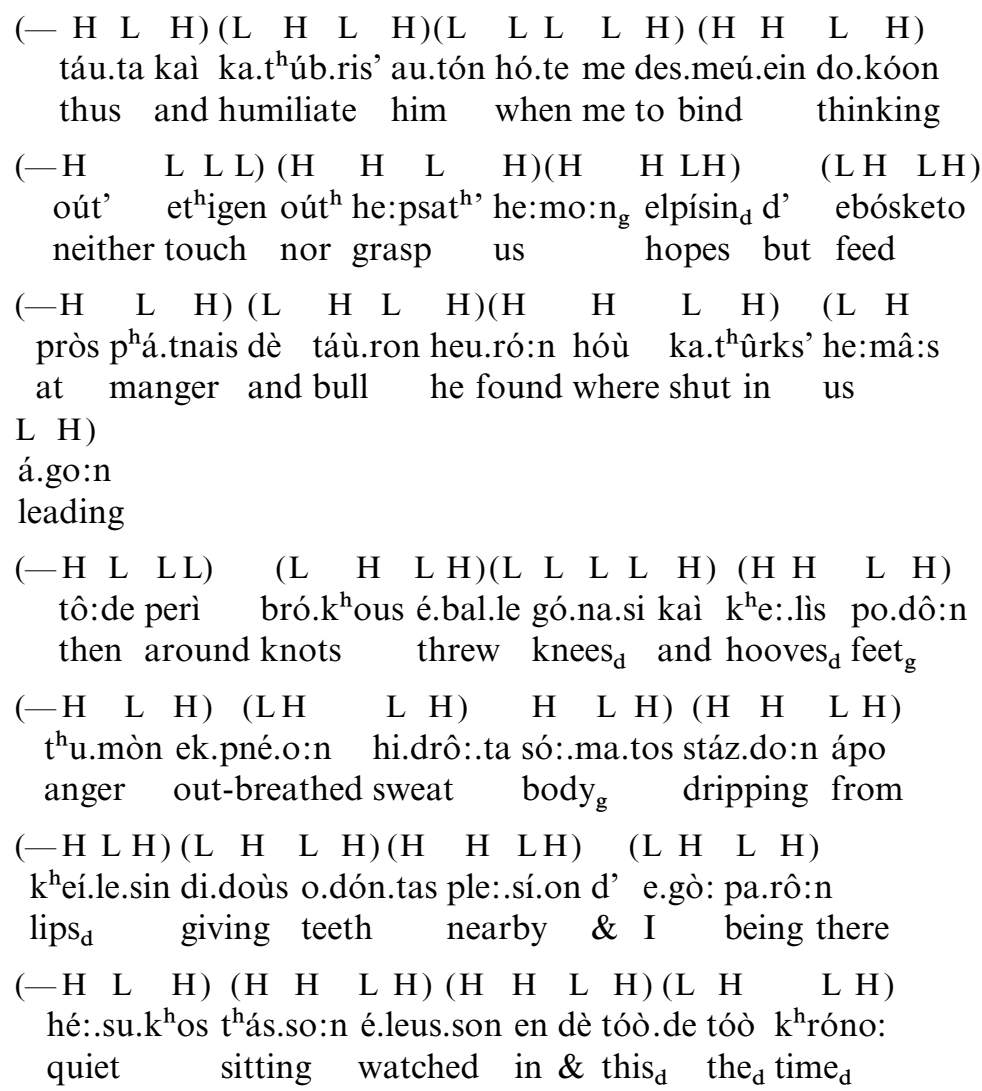

'This is how I humiliated him: in thinking that he was binding me he neither touched me nor grasped me, but fed on hopes.

And finding a bull at the manger, where he led and imprisoned me, he threw a snare around its knees and hoofed feet,

panting his anger out, sweat dripping from his body,

biting his lips. I was there nearby

and watched, sitting silently. And at this time ...'

This meter is often called trochaic tetrameter catalectic, and those who analyze it as such (e.g. Raven 1962: 34) treat it as having final catalexis: $(\mathrm{HLH} \sigma)(\mathrm{HLH} \sigma)(\mathrm{HLH} \sigma)(\mathrm{HLH}-)$. For this reason we should discuss why the catalexis is initial and why the meter is better analyzed as iambic than as trochaic.

Following West (1982: 40), Maas (1962), and others, we note that "trochaic" tetrameter and iambic trimeter mix freely in Greek and share 
a number of common characteristics including position of the caesura and major bridges. If we were to analyze the tetrameter with final catalexis, all of this would be coincidental because tetrameter will then have the opposite type of foot to iambic trimeter. The former would run $\phi \mathrm{L} \phi \sigma$ and the latter would run $\sigma \phi \mathrm{L} \phi$. But if we assume that the catalexis is initial, the positions of the caesura and bridges line up exactly and we find an understanding for how these two meters could be freely mixed in with one another. For these reasons, West recognizes "trochaic tetrameter" as essentially the same meter as iambic trimeter (1982: 40) and we follow him in this regard. We will therefore refer to it henceforth as iambic tetrameter catalectic, since it has the same type of metron as the tragic trimeter, but with four metra rather than three. A schema for the meter is given below.

(64) Iambic tetrameter catalectic

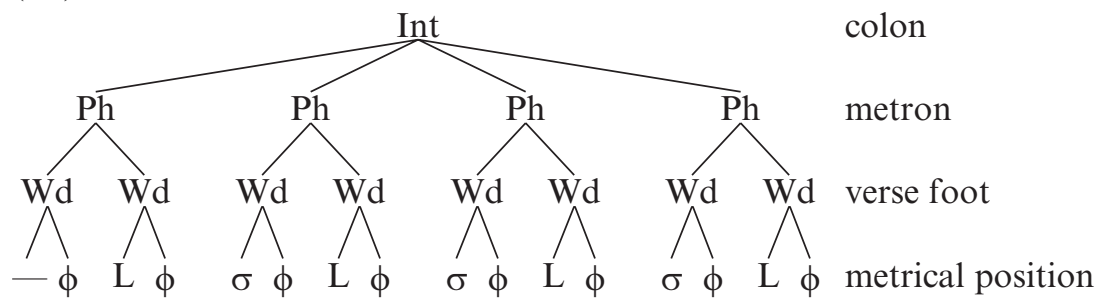

This meter differs from iambic trimeter in two respects: it has four metra rather than three and it has one unfilled metrical position at the beginning of a line. This makes it even more marked than the trimeter since the unmarked case (acatalectic dimeter) is to have two metra to the line and no catalexis.

Why is catalexis initial rather than final? Recall that every metron needs to violate NOLAPSE and that the final metrical position of a line is always counted as heavy (ANCEPS). Now consider what happens with final catalexis $(a, b)$ versus initial catalexis $(c)$.

(65) Comparing initial and final catalexis

\begin{tabular}{|l|l||l|l|}
\hline & & ANCEPS & NOLAPSE \\
\hline \hline a. & $\begin{array}{c}{[\mathrm{LH} \mathrm{LH}][\mathrm{LH} \mathrm{LH}]} \\
{[\mathrm{LH} \mathrm{LH}][\mathrm{LH} \mathrm{L}-]}\end{array}$ & $* !$ & IIII \\
\hline b. & $\begin{array}{c}{[\mathrm{LH} \mathrm{LH}][\mathrm{LH} \mathrm{LH}]} \\
{[\mathrm{LH} \mathrm{LH}][\mathrm{LH} \mathrm{H}-]}\end{array}$ & & III $<$ I $>!$ \\
\hline c. $\infty$ & $\begin{array}{l}{[-\mathrm{H} \mathrm{LH}][\mathrm{LH} \mathrm{LH}]} \\
{[\mathrm{LH} \mathrm{LH}][\mathrm{LH} \mathrm{LH}]}\end{array}$ & & IIII \\
\hline
\end{tabular}


Candidate (a) has final catalexis and consistent violation of NOLAPSE, as desired, but removing the final metrical position leaves an $\mathrm{L}$ as last position, in violation of ANCEPS. Candidate (b) has a final $\mathrm{H}$ in compliance with ANCEPS but fails to violate NOLAPSE in the last metron ( $\mathrm{LHH}-$ ). Candidate (c) meets all requirements by virtue of applying catalexis at the left edge. Catalexis itself must be stipulated for this meter, but that catalexis is initial is forced by independently needed constraints.

\subsection{Markedness}

The formal analysis of iambic meter in Greek requires mention of the constant lapse across the second and third metrical positions in every verse foot. This may be done as follows.

(66) "Iambic"

\begin{tabular}{|c|}
\hline NOLAPSE \\
\hline \hline I \\
\hline
\end{tabular}

(66) simply states that iambic metra contain stress lapses. This picks out the right combinations of verse feet fairly easily, as we have seen.

The two lengths of iambic meter we find can also be described in terms of how much they deviate from a dimeter.

(67) Trimeter

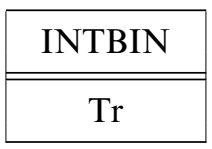

(68) Tetrameter

\begin{tabular}{|c|}
\hline INTBIN \\
\hline \hline $\mathrm{Te} \mathrm{Te}$ \\
\hline
\end{tabular}

The intonational phrase of a line of trimeter branches once more than it would if it were a dimeter, hence one distinctive violation ( $\mathrm{Tr}$ ) in (67). The intonational phrase of a line of tetrameter branches twice more than it would if it were a dimeter, hence two distinctive violations ( $\mathrm{Te} \mathrm{Te}$ ) in (68).

Summing up our section on iambs, we have shown that the only surface-true rhythmic fact of iambic meter in Greek is that each and 
every metron violates NOLAPSE exactly once. Iambic meter is thus the phonological opposite of dactylic meter, which violates NOCLASH. Indeed, we can now see why later Greek metricians called the six-foot meter of tragedy trimeter and the six-foot meter of epic hexameter. They were apparently counting how many times the rhythmic anomaly occurred per line. In epic there are six violations of NOCLASH per line because there is stress clash in every verse foot (HLL or HH). In drama there are only three violations of NOLAPSE per line because there is stress lapse only between PAIRS of verse feet.

\section{Spondaic meter}

Spondaic meter is a rare meter used for short religious poems, solemn marches, and the like. It is clearly somewhat special in Greek, but we consider it here because it shows clearly just how arrhythmic a meter can be and how well violation of rhythmic expectations can be used as a defining aspect of meter. Each line has five spondaic $(\mathrm{HH})$ verse feet.

(69) Spondaic invocation (Page 1962: 0941)

$$
\begin{aligned}
& \left(\begin{array}{lllll}
\mathrm{H} & \mathrm{H}
\end{array}\right)\left(\begin{array}{llll}
\mathrm{H} & \mathrm{H}
\end{array}\right) \quad\left(\begin{array}{lll}
\mathrm{H} & \mathrm{H}
\end{array}\right)\left(\begin{array}{ll}
\mathrm{H} H \\
\mathrm{H}
\end{array}\right) \quad\left(\begin{array}{ll}
\mathrm{H} & \mathrm{H}
\end{array}\right) \\
& \text { spén.do:men táis mná:.mas pai.sìn moú.sais } \\
& \text { we pour the } \text { memory }_{g} \text { children }_{d} \text { Muses }_{d} \\
& \left(\begin{array}{lll}
\mathrm{H} & \mathrm{H}
\end{array}\right) \quad\left(\begin{array}{lll}
\mathrm{H} & \mathrm{H}
\end{array}\right)\left(\begin{array}{llll}
\mathrm{H} & \mathrm{H}
\end{array}\right)\left(\begin{array}{lll}
\mathrm{H} & \mathrm{H}
\end{array}\right)(\mathrm{HH}) \\
& \text { kaì tô:i mou.sár. } \mathrm{k}^{\mathrm{h}} \mathrm{O}: \mathrm{i} \text { to:i la:.tóùs hui.éì } \\
& \text { and the }{ }_{d} \text { muse-leader the } \text { Leto }_{g} \text { son }_{d}
\end{aligned}
$$

'We pour [this] to the muses, children of Memory, and to their leader [Apollo], the son of Leto.'

\section{1. "Spondaic"}

Like dactylic meter, the spondaic invocation contains clashes in every verse foot, but where dactyls alternate $(\mathrm{H} \mathrm{H})$ with $(\mathrm{H} \mathrm{LL})$, spondaic meter allows only the former. The spondee is thus a related but more constrained verse foot than the dactyl, a fact that should be reflected in the analysis. We note that none of the metrical positions in spondaic meter has two syllables, in violation of the constraint FTBIN- $\sigma$ discussed above in relation to the Greek dactyl, which tends to be realized as HLL rather than $\mathrm{HH}$. Just as every verse foot in spondaic meter violates NOCLASH, so does every verse foot violate FTBIN- $\sigma$. We thus treat 
distinctive violation of both constraints as desiderata for this most marked of meters.

\subsection{Pentameter}

The spondaic invocation contains five verse feet and so we call it pentameter. There is not a lot of research to build on for the spondaic invocation, so we import some of what has been learned from pentameters in other languages, especially Spanish, Italian, and English. An overview of the structure is given below, following Piera (1980), Nespor and Vogel (1986), and Youmans (1989), who posit two structures for pentameter.

(70) Spondaic invocation<smiles>[H][R11]([H])([H])C([AlH])[Y14]([H])([H])[H]</smiles>

or

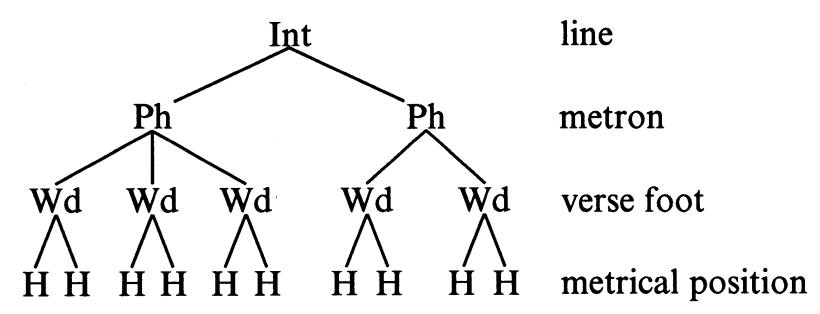

Not enough is known about spondaic invocations to determine whether one of these structures is better suited than the other; Piera (1980) and Hayes (1988) suggest that the $2+3$ structure is unmarked cross-linguistically, but we will not pursue the issue for Greek. What we do want to stress is how close both trees are to the unmarked dimeter discussed above. The only difference is that one of the metra in the pentameter branches twice instead of the expected once. Given a way to encode this simple difference, the fact that one has ten verse feet here instead of the expected eight in a dimeter falls out unproblematically. 


\subsection{Markedness}

Spondaic invocations are marked by the same stress clash as dactylic hexameter, in violation of NOCLASH. In addition, all ten metrical positions are monosyllabic, in frank violation of FTBIN- $\sigma$, which favors moraic trochees shaped LL over ones shaped $\mathrm{H}$. We may formalize this as a desideratum for spondaic meter.

(71) Spondee

\begin{tabular}{|c|}
\hline FTBIN- $\sigma$ \\
\hline \hline S S \\
\hline
\end{tabular}

This says that a spondaic verse foot contains two metrical positions (moraic trochees) that each fails to branch into two syllables. The only verse foot that violates FTBIN- $\sigma$ twice and NOCLASH is HH.

The pentameter part of the spondaic invocation requires a single violation of binarity at the level of the phonological phrase, as follows,

(72) Pentameter

\begin{tabular}{|c|}
\hline PHBIN \\
\hline \hline $\mathrm{P}$ \\
\hline
\end{tabular}

which states that a line of pentameter has one phonological phrase that branches once more than it would if it were a normal dimeter. The ternary branching phonological phrase may be realized in the first half of the line or the second, (70), at least in Spanish and English pentameter.

\section{Rhythm and meter}

In this section we look at an asymmetry that crops up in our treatment of metrical constraints (section 6.1) and then review our proposals for understanding line length, rhythm, and catalexis in Greek meters and beyond (section 6.2).

\subsection{An asymmetry}

There is an interesting asymmetry between distinctive violations of constraints that regulate line length (catalexis, binarity) and distinctive violations of constraints that regulate rhythm. The former always involve an 
existential violation (some $\mathrm{x}$ isn't binary) while the latter always involve a universal violation (every $\mathrm{x}$ is arrhythmic). Why should this be?

A clear possibility is that this is merely an artifact of our analysis, and we would not want to rule out this possibility too hastily. But the question can be stated more generally. Why do we find catalexis once per line rather than once per verse foot? Why isn't it enough in dactylic meter to have one HLL or HH per line, why must it be all six?

Suppose that the arrhythmy in dactylic hexameter involved only one violation of NOCLASH in each line; or that the arrhythmy in iambic trimeter involved only one violation of NOLAPSE per line. This violation would not be very salient because there is nothing unusual in Greek in having stress clash or lapse; they are in fact very common indeed in all forms of speech and prose in Greek as in most languages. In order to be noticeable at all, violations of NOCLASH and NOLAPSE must be pervasive and regular. So rhythmic effects like clash and lapse are found at the surface in every single metron - this gives the meter its distinctive rhythmic feel.

The opposite applies to distinctive violations of binarity. Suppose that catalexis applied to the beginning of every verse foot in tetrameter instead of just the line-initial verse foot. The result would be something like $(-\mathrm{HLH})(-\mathrm{HLH})(-\mathrm{HLH})(-\mathrm{HLH})$, with 12 filled metrical positions. ${ }^{15}$ Such a line, we imagine, would invite immediate reparsing as six acatalectic verse feet, (HL) (HH) (LH) (HL) (HH) (LH) - that is, as a random set of verse feet instead of a set of repeated verse feet. Taking out one position from every metron yields an even number of verse feet that can always be reinterpreted without catalexis. The main surface cue for catalexis is an odd number of metrical units on the surface, but this can only be achieved if distinctive violation of binarity constraints happens once per line. This, we suspect, is why constraints that regulate line length and rhythm operate differently.

\subsection{A broader picture}

We have proposed an account of Greek meter based solely on prosodic constraints that regulate binarity, rhythm, and faithfulness. Before we look at other theories of Greek meter, we would like to sum up our proposals and sketch how our model is meant to work for meter more generally.

Our analysis makes use of the following very general constraints.

(73) Binarity

a. INTBIN

Intonational phrases (lines) branch once. 
b. PHBIN

Phonological phrases (metra) branch once.

c. WDBIN

Phonological words (verse feet) branch once.

d. FTBIN $-\mu$

Phonological feet (metrical positions) contain two moras.

e. FTBIN- $\sigma$

Phonological feet (metrical positions) contain two syllables.

(74) Rhythm and weight
a. NOCLASH

Stressed syllables are not adjacent.

b. NOLAPSE

Unstressed moras are not adjacent.

c. PROKOSCH

(75) Faithfulness

Stressed syllables are heavy.
a. FILL
Syllable positions must be filled with underlying segments.
b. PARSE
Underlying segments must be parsed into syllable structure.

The constraints in (74) and (75) are noncontroversial, at least within optimality theory, and are cross-linguistically supported. The two FTBIN constraints are also well motivated in terms of languages that have either moraic feet (like Greek) or syllabic feet (cf. Hayes 1995 and references therein); the rest of the binarity constraints in (73) are harder to justify in terms of nonmetrical phonology, though it has been claimed that prosodic structure is generally binary (Kager 1989: 130ff., 1993; Prince 1989: 55ff.; Hayes 1995).

We begin with the simplest proposal, that catalexis is a marked state and that the markedness can be understood as violation of a constraint (FILL) that requires all metrical positions in a line to be filled with text. There is a related notion in traditional metrics, extrametricality, for lines that have more text than meter. This situation is also taken to be the marked case and can be understood as violation of a constraint (PARSE) that requires all text in a line to be part of a metrical position (cf. Prince and Smolensky 1993).

(76) Catalexis and extrametricality

\begin{tabular}{|l||c|}
\hline & FILL \\
\hline \hline Acatalectic & \\
\hline Catalectic & $\mathrm{C}$ \\
\hline
\end{tabular}




\begin{tabular}{|l||c|}
\hline & PARSE \\
\hline \hline Metrical & \\
\hline Extrametrical & E \\
\hline
\end{tabular}

Thus a basic insight into meter, that the text is supposed to match a given pattern, can be handled insightfully by importing constraints developed in phonology. Again, the matching has two sides to it: the text is supposed to fill the meter and the meter is supposed to parse the text.

The Greek meters we have looked at do not make systematic use of extrametricality, but Greek lyric meters do (Golston and Riad 1999). Greek lyric meters are for the most part very strict indeed about where $\mathrm{H}$ and $\mathrm{L}$ syllables must go; so it is surprising to find that many lyric meters begin with one or two syllables whose quantity is completely unregulated. These metrically unregulated (extrametrical) positions are known as the Aeolic Base in Greek metrics (Maas 1962: section 33; Raven 1962: section 132).

A more common metrical regularity is line length, almost a sine qua non of meter. We have looked at five different types of line in terms of length, from dimeter to hexameter, and have proposed an analysis of them in terms of two constraints that regulate binarity (INTBIN and PHBIN), as follows.

(77) Line length

\begin{tabular}{|l||l|l|}
\hline & INTBIN & PHBIN \\
\hline \hline Dimeter & & \\
\hline Trimeter & $\mathrm{Tr}$ & \\
\hline Tetrameter & $\mathrm{T} \mathrm{T}$ & \\
\hline Pentameter & & $\mathrm{P}$ \\
\hline Hexameter & & $\mathrm{H} \mathrm{H}$ \\
\hline
\end{tabular}

The unmarked line length according to our analysis is the four-word dimeter, in line with Burling's (1966) cross-linguistic findings for the structure of nursery rhymes. From a purely Greek perspective it makes sense to say that tetrameter is more marked than trimeter, as trimeter is by far the more common meter for dialogue. But it makes much less sense to claim that pentameter is less marked than hexameter since there are great tomes written in hexameter but only short snippets written in pentameter in Greek. But this difference is probably due to factors other 
than markedness of line length. Greek pentameter is spondaic (HH) while hexameter is dactylic (HLL or $\mathrm{HH}$ ); it seems possible, therefore, that spondaic pentameter is less common than dactylic hexameter because of the difficulty of writing extended texts using only heavy syllables. The fact that pentameter in other languages (Romance, Slavic, and Germanic especially, under conditions different from those in Greek) has been very successful adds some weight to the idea that line length is not what's wrong with Greek pentameter.

In any case, our analysis provides a way of understanding all meters in terms of markedness, that is, in terms of deviation from a dimeter norm. Since markedness has played an important role in our understanding of phonology, we are hopeful that it will play an equally important role in our understanding of meter.

The final area we have looked at here involves rhythm and, more controversially, the claim that most Greek meters are not rhythmic at all, in their definitions. In some sense this should be a straightforward claim to make. If one meter is perfectly rhythmic the others must not be. Let us review the proposal and see what it is meant to do. We have argued that anapestic meter is rhythmically unmarked because it has no consistent violations of NOCLASH and no adjacent stressless moras that would ever violate NOLAPSE. We arrive at this conclusion simply by parsing anapestic texts into moraic trochees and blindly applying the Greek rules for prominence. We do the same for dactyls and find that the metrical prominences pattern in a certain way when we look at the syllable level: every verse foot has a stress clash in it, in violation of NOCLASH. A similar result is found for iambic meter, but this time we find that the metrical prominences produce a pattern at the moraic level: every metron has a stress lapse in it, in violation of NOLAPSE. When we come to spondaic meter we find the same incessant stress clash that was found in dactylic meter but with an additional twist. No metrical position is disyllabic, in violation of FTBIN- $\sigma$. This meter is thus doubly marked because the verse feet are both short and contain a clash.

(78) Rhythm and arrhythmy

\begin{tabular}{|l||l|l|l|}
\hline & NOCLASH & NOLAPSE & FTBIN- $\sigma$ \\
\hline \hline Anapest & & & \\
\hline Dactyl & D & & \\
\hline Iamb & & I & \\
\hline Spondee & S & & S \\
\hline
\end{tabular}


The data, we feel, speak for themselves once we scan the texts with Greek prominence relations (moraic trochees) in mind. The question that remains is whether all this arrhythmy is intentional or just a byproduct of something else. This is a difficult question to answer head on, but we feel it is highly unlikely that the only systematic and surfacetrue rhythmic regularities in a number of meters would all be accidental. We find it much more plausible that Greek poets made use of this markedness to differentiate grown-up poetry from nursery rhymes. No one has ever suggested that Greek meter was simple, and we are merely proposing that some of the complexity is in some sense contra naturam, that is, prosodically marked. This is a commonplace notion in music and one that we think can profitably be imported into the study of meter.

A full typology of meters in terms of violations of these constraints would include very marked meters in which a number of constraints were violated. Such meters are predicted to be very rare (because ex hypothesi they are very marked), but it might be worth considering what they would look like. Let us begin by expanding (77) to include types of meter that violate INTBIN three times per line (meter $\mathrm{X}$ ) or PHBIN three times per line (meter $Y$ ) or both INTBIN and PHBIN one time per line (meter Z).

(79) Real and unattested (italicized) Greek lengths

\begin{tabular}{|l||l|l|}
\hline & INTBIN & PHBIN \\
\hline \hline Dimeter & & \\
\hline Trimeter & $\mathrm{Tr}$ & \\
\hline Tetrameter & $\mathrm{T} \mathrm{T}$ & \\
\hline meter $X$ & $X X X$ & \\
\hline Pentameter & & $\mathrm{P}$ \\
\hline Hexameter & & $\mathrm{H} \mathrm{H}$ \\
\hline meter $Y$ & & $Y Y Y$ \\
\hline meter $Z$ & $Z$ & $Z$ \\
\hline
\end{tabular}

Meter X would look like the following if it were anapestic. 
(80) Unattested anapestic meter X

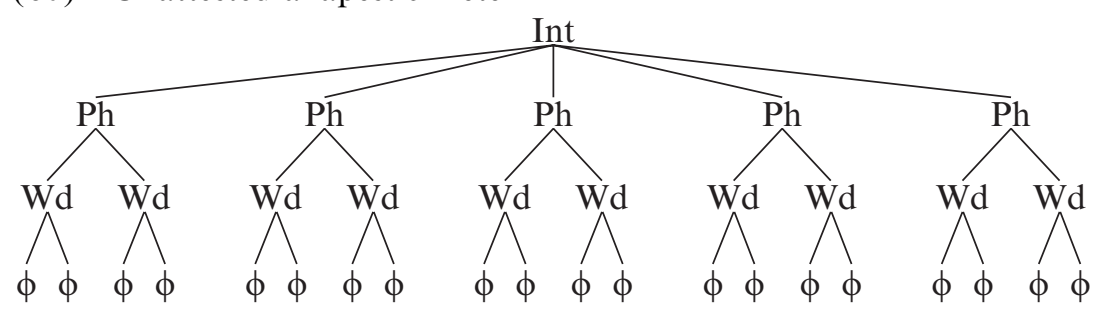

No such meter occurs in Greek, where the maximal number of verse feet is eight (anapestic tetrameter). We cannot of course exclude this type of meter from the range of possible meters in Greek, but we can note that it is formally more marked than any existing meter in the language and thus still account for its nonexistence in the tradition in terms of markedness.

Meter $\mathrm{Y}$ would be instantiated in a dactylic meter as follows.

Unattested dactylic meter $Y$

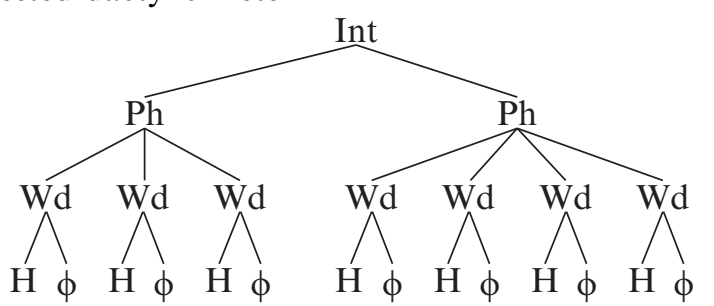

Again, we find no such line in Greek and we may attribute this to markedness. A line that violates PHBIN more than twice falls outside the limits of markedness that Greek poets explored. It is not an impossible line, but is an unattested line in Greek.

Meter $\mathrm{Z}$ would look like the following in an iambic setting.

(82) Unattested iambic meter $Z$

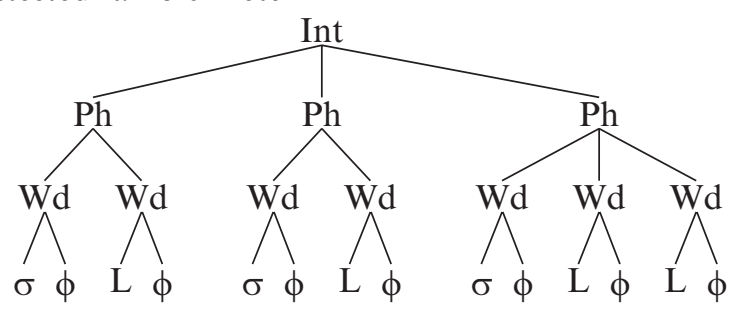

This type of meter also falls outside of the extant types and our analysis provides a way of understanding why: no Greek meter violates both INTBIN and PHBIN. 
Turning now to unattested Greek rhythmic patterns, we may expand (78) to include other possible but unattested meters as follows.

(83) Real and unattested (italicized) Greek rhythms

\begin{tabular}{|l||l|l|l|}
\hline & NOCLASH & NOLAPSE & FTBIN- $\sigma$ \\
\hline \hline Anapest & & & \\
\hline Dactyl & $\mathrm{D}$ & & \\
\hline meter $Q$ & $D D$ & & \\
\hline Iamb & & $\mathrm{I}$ & \\
\hline meter $R$ & & $I I$ & \\
\hline Spondee & $\mathrm{S}$ & & $\mathrm{S}$ \\
\hline meter $S$ & $D$ & $I$ & \\
\hline
\end{tabular}

Meter Q would have to contain two cases of stress clash in each verse foot, which is impossible given binary verse feet: ( $\mathrm{xx} \mathrm{xx}$ ) would have to include four moraic trochees (one per $\mathrm{x}$ ), in violation of WDBIN, which is never violated in extant Greek meters. So meter $Q$ is not possible unless an even more marked meter is constructed, namely one with very large verse feet. We have no way of excluding such a meter in principle, of course, but we do predict (correctly we think) that such a meter is highly unlikely.

Meters $\mathrm{R}$ and $\mathrm{S}$ are highly marked for the same reason. In order for a verse foot to have two cases of stress lapse in the same verse foot it would need to have more than two pairs of moraic trochees, in violation of WDBIN; this makes R highly marked and thus highly unlikely. And in order for a verse foot to have both stress lapse (HL or LLL) and stress clash (HH or HLL) in the same foot it would have to branch three times in violation of WDBIN; this makes $\mathrm{S}$ highly unlikely.

A full typology falls outside the scope of this paper, but we hope that the foregoing remarks show the scope of our claims. Our analysis arrays different types of meter along a set of scales from less-to-more marked lengths and rhythmic types. We have shown that the less-marked of these occur in Greek and that the more-marked do not, showing that we can account both for what does occur and what does not occur in Greek meter.

But the best defense is often a good offense, so we will turn now to what we see as the major weakness of existing accounts of Greek meter. 


\section{Comparison with other theories}

Here we consider two other types of analysis, one traditional and one generative (Prince 1989) to show that the present analysis is the only contender that offers strong generalizations that are both meaningful and surface-true.

\subsection{Traditional analysis}

We cannot go into all the details of the extensive literature on Greek meter. Rather, we would like to mount a broad criticism of central (often implicit) claims of the tradition as a whole, centering on its inability to insightfully capture the surface patterns of Greek poetry. Our main concern is that traditional analysis provides no coherent account of the notions anapest, dactyl, and iamb.

We can begin with the anapest. Traditional analysis is needlessly abstract and derivational. It posits a basic anapestic LLH and derives the other verse feet by two metrical rules that split apart $\mathrm{H}$ or contract LL (e.g. West 1982: 19ff., 193-199; see Nagy 1974: 49-102 for a diachronic version of the same). CONTRACTION of LL turns the underlying anapest LLH into a spondee HH. RESOLUTION of $\mathrm{H}$ turns underlying LLH into proceleusmatic LLLL. CONTRACTION AND RESOLUTION together turn LLH into dactylic HLL. Assuming that less-derived types are more basic, this analysis leads us to expect that most verse feet will be LLH (the basic foot), followed by HH and LLLL (derived by the application of a single rule), and finally by HLL (derived by the application of two rules), that is, LLH $\gg$ HH, LLLL $\gg$ HLL. As we saw above, however, NONE of these expectations is met. Rather, we find the order to be $\mathrm{HH} \gg \mathrm{LLH} \gg \mathrm{HLL} \gg$ LLLL.

We see no good way of amending the traditional analysis to get these facts. We could make the basic foot a spondee ( $\mathrm{HH})$ and derive the rest by application of the resolution rule, getting us HH (basic) $\gg$ LLH, HLL (resolution once) $\gg$ LLLL (resolution twice). This would correctly get the facts but at great cost. The central claim of traditional analysis is that anapestic meter is ANAPESTIC, not spondaic. It is worth stressing again that the association of the anapest with a particular rhythm (di di dum) is not warranted in Greek (West 1982: 23). The very idea of having a basic verse foot with foot substitutions is absurd, rhythmically speaking. The idea that di di dum is the real pattern and that dum di di, dum dum, and $d i d i d i d i$ are simply variations on a rhythmic theme can't be right, since the various feet have opposed rhythmic properties. In traditional 
terms, di di dum is rising while dum di di is falling, so it is hard to see how a falling rhythm can substitute for a rising rhythm and still remain the same type of rhythmic entity. Worse yet, dum dum and di di di di are neither rising nor falling, so it looks as if there will be no rhythm on the surface at all for some verse feet.

Furthermore, as we have seen, these are not the right Greek rhythms in any case. Equating $\mathrm{H}$ with prominent and $\mathrm{L}$ with nonprominent is a mistake to begin with (Maas 1962; Raven 1962; Allen 1973; etc.). Again, recall that the stress matrix in Greek is equally H or LL (Allen 1973). If we plug this into LLH we get dum di dum not di di dum; so it makes no sense to treat LLH as rhythmically anapestic to begin with. Similarly for HLL (dum dum di, not dum di di) and LLLL (dum di dum di, not di $d i d i d i$ ). If we take rhythm in anapestic meter seriously we are left with the inescapable conclusion that anapestic meter doesn't care about rhythm. No surface-true rhythmic characterization is possible if we look to LLH as somehow basic; and surface-false characterizations are worthless lest there are no surface-true generalizations to be had.

We have shown that there are two simple surface-true generalizations about anapestic meter, namely that it is perfectly rhythmic at the moraic level, and that it respects binarity of the metrical foot. At the syllable level it looks quite chaotic. We account for the rich surface array of anapestic meter by defining a class of well-formed verse feet (HLL, LLH, LLLL, HH) and then ordering them in terms of how well they satisfy other, less important, ranked but violable constraints (PROKOSCH, NOCLASH). The verse foot that satisfies them best $(\mathrm{HH})$ relative to the other permissible verse feet is the most common verse foot; those that violate them some more are the next most common (LLH and HLL, in that order); and the one that violates them most is the least common (LLLL).

So why would the perception that anapestic meter is essentially rising (LLH, or di di dum) have had such an unchallenged status in traditional analysis? The main reason is that in the anapestic tetrameter catalectic the last full foot is always LLH. Thus it makes some degree of sense to treat all of the other verse feet as basically LLH as well. Or does it? This is the form normally found in Aristophanes, but the LLH is contracted to $\mathrm{HH}$ in the last full foot in other comic writers like Cratinus, Crates, and Philyllius (West 1982: 94). If we want to characterize the meter of all these authors' works, we will have to drop the part about the last full foot always being LLH.

Moreover, there is actually very little evidence for the claim that the LAST metrical position of this meter is catalectic rather than the first. 
Consider what happens if we scan the following line with initial catalexis rather than final catalexis.

(84) Aristophanes Knights, 773

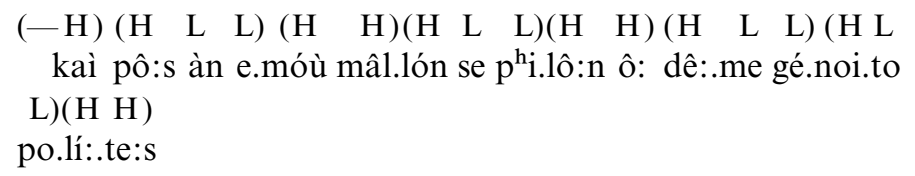

Now the generalization for Aristophanes is quite different. Lines uniformly end in (HLL) (HH), just as they usually do in Homer. Thus if catalexis is initial in the anapestic tetrameter, the end of a line is basically dactylic (looking at the penultimate foot) or spondaic (looking at the last). We do not think the issue is easily resolved either way. We merely want to point out that the basic assumption behind the traditional analysis (that the catalectic tetrameter has final catalexis) is not a necessary or even a useful assumption.

We are aware of no strong evidence for bridges in anapestic meter, and the evidence from word division doesn't tell us much. If one assumes final catalexis, one regularly finds word division after the second metron and usually after the first as well (Raven 1962: section 84); this is called diaeresis (coincidence of word and verse-foot division) and is what we find in anapestic dimeter. If one assumes initial catalexis, on the other hand, one regularly gets word divisions within feet rather than across them; this goes under the name of ceasura (word boundary inside of foot boundary) and is what we find in dactylic hexameter. So there are good antecedents for either type of analysis, and word division cannot help us determine whether this type of meter has initial or final catalexis.

Let us turn then to traditional analyses of dactylic hexameter, where there is no catalexis to worry about. Tradition presupposes a basic HLL verse foot and derives HH by CONTRACTION. But recall that dactyls account for only $60 \%$ of the verse feet in the meter - all the rest are spondees. Traditional analysis is thus inherently abstract in a serious way. Dactylic rhythm only occurs at a level of analysis abstracted away from the actual text, BEFORE CONTRACTION, as it were. If we look at the surface, the allegedly basic pattern doesn't surface much more than chance would lead us to expect. Traditional analyses stress that the penultimate verse foot is usually HLL, but this observation should not commit us to seeing the entire line as a succession of dactyls. The final verse foot, after all, is always $\mathrm{HH}$, but this has not led anyone to speculate that the whole line is really a succession of spondees. Indeed, we could just as easily analyze hexameter as underlyingly spondaic ( $\mathrm{HH})$ with 
RESOLUTION possible at the end of any verse foot but the last. But this would be no better than the traditional analysis. Rather than trying to decide whether HLL or $\mathrm{HH}$ is the real verse foot, it seems best to admit that HLL and HH are both real verse feet in this meter. Any small discrepancies in which occurs where and how often can be dealt with using violable constraints (cf. [46] and [47] above). This allows us to separate what is always true of the meter (clash in every foot) from what is only a tendency (HLL vs. HH).

Another common misunderstanding of HLL is that it is inherently rhythmic, essentially $d u m d i d i$. The acceptable spondaic variation would then be dum dum. As we have already pointed out, this must be wrong for Greek (cf. West 1982: 23) because the phonology of the language itself assigns prominence to the first two light syllables as well as to a single heavy H. HLL, therefore, is not dum di di, but rather dum dum di, the first $\mathrm{L}$ being prominent. Once we interpret the meter in terms of Greek phonology, we see that HLL contains a surface stress clash just as $\mathrm{HH}$ does - and that stress clash is the defining rhythmic property of the meter.

The wide array of permissible iambic metra would also seem to be problematic for traditional analysis, but the fact that the initial $\mathrm{LH}$ can be realized as HH, LLLL, HLL, or LLH does not seem to be perceived as a problem. Neither does the fact that the second $\mathrm{LH}$ can occur as L LL. How might this be accounted for using CONTRACTION and RESOLUTION? Recall that the commonest foot types run $\mathrm{LH}>\mathrm{HH}>\mathrm{L} \mathrm{LL}>\mathrm{HLL}$. If LH is basic, RESOLUTION can only get us LLL and the second half of HLL.

However, there are two other problems that need to be solved. First, the initial L of LHLH can also surface as a H, but neither RESOLUTION $(\mathrm{H} \rightarrow \mathrm{LL})$ nor CONTRACTION $(\mathrm{LL} \rightarrow \mathrm{H})$ can bring this about. Some other rule must be added to the metrical grammar to make $\mathrm{L}$ into $\mathrm{H}$; or the basic form must be $\sigma \mathrm{HLH}$, in which case the verse feet are no longer both iambic. Second, the medial L of LHLH can never be realized as H. So whatever rule turns the initial $\mathrm{L}$ into a $\mathrm{H}$ must be strictly prohibited from turning the middle $\mathrm{L}$ into a $\mathrm{H}$. We conclude that tradition analysis has no nonstipulative solution to these issues, whereas on our account, the issues do not even arise.

\subsection{Metrical forms (Prince 1989)}

Prince's (1989) study of Greek and Arabic meters follows previous work in generative metrics (Halle and Keyser 1971, 1977; Kiparsky 1977; 
Hayes 1989; Hammond 1991) in defining all verse feet as INHERENTLY RHYTHMIC units. Verse feet differ both in terms of prominence (strongweak, weak-strong, etc.) and in terms of content (LLH, HLL, LH, etc.). We find three problems with the analysis as Prince presents it.

First, there is the excessively large set of verse feet. Prince has two types of verse foot, those that branch once ("binary") and those that branch twice ("split-binary"). Binary verse feet have the structure [M M], where each M may contain one of H, LL, L or $\sigma$. Split-binary verse feet embed one binary verse foot inside another: [M [MM]] or [[MM] M ].

(85) Binary and split-binary verse feet

$\begin{array}{lll}\text { Binary } & {\left[\begin{array}{ll}M & M\end{array}\right]} \\ \text { Split binary } & {\left[\begin{array}{ll}M M & M\end{array}\right]} \\ & {\left[\begin{array}{ll}M & {[M M}\end{array}\right]}\end{array}$

$\mathrm{H}, \mathrm{LL}, \mathrm{L}$, and $\sigma$ combine to make 16 binary feet, as follows.

(86) Binary verse foot types

\begin{tabular}{|l|l|l|l|}
\hline L L & L H & L $\sigma$ & L LL \\
\hline H L & H H & H $\sigma$ & H LL \\
\hline$\sigma$ L & $\sigma$ H & $\sigma \sigma$ & $\sigma$ LL \\
\hline LL L & LL H & LL $\sigma$ & LL LL \\
\hline
\end{tabular}

This is a reasonable set of verse feet - we have nine, see (21) - but when we add in all the possible split-binary verse feet the set grows very quickly. There are $64\left(4^{3}\right)$ left-branching and 64 right-branching splitbinary types if we allow every metrical position to be $\mathrm{H}, \mathrm{LL}, \mathrm{L}$, or $\sigma$. Adding in the binary verse feet give us fully 144 types of verse foot in the theory.

(87) 144 possible verse feet

$$
\begin{array}{lllrl}
\text { Binary } & 4^{2} & {[\mathrm{M}} & \mathrm{M}] & 16 \\
\text { Split binary } & 4^{3} & {[[\mathrm{MM}]} & \mathrm{M}] & 64 \\
& 4^{3} & {[\mathrm{M}} & [\mathrm{MM}]] & \frac{64}{144}
\end{array}
$$

And 144 is a conservative estimate of Prince's metrical system. To keep the figure low we have made two assumptions that drastically limit its size. First, we have not factored in differences in SW labeling, which are completely unnecessary as elements of analysis in Greek meter. Second, we have not allowed doubly split-binary feet (MM MM), an option 
clearly predicted by the system that Prince rejects only by fiat; such feet would swell the number of possible verse feet even further. Under even the strictest set of assumptions, then, Prince's analysis allows a very large number of foot types.

Second, the strong/weak labeling serves no purpose in the analysis. What really differentiates meters is what their metrical positions contain; whether one is stronger or weaker is both irrelevant for any generalizations about the meter and completely predictable from the contents of the positions. Given [LH] we invariably opt for the analysis [WS]. Our account uses no such notions, limiting itself strictly to what is observable on the surface.

Third, there is the issue of binarity. The structure [M [MM]] involves a richer notion of binarity than is generally encountered in phonology, where strict layering (Selkirk 1984, 1986, 1995) rules out recursion of prosodic structure. Just as there are no syllables within syllables, we expect that there are no feet within feet or metrical positions within metrical positions. For this reason we have limited ourselves to strict layering, as any of our charts shows.

To summarize, our proposal is much more conservative than Prince's. Our account has nine surface feet rather than 144; it makes no use of gratuitous distinctions like strong and weak; and it requires no recursive prosodic structure. ${ }^{16}$

\section{Conclusion: meter as phonology}

We can think of Greek meters as modified Greek grammars in which a few prosodic concerns come to dominate the output, such that speech takes on a peculiar quality. It may evince perfect binarity and perfect rhythm (anapestic), arrhythmy in the form of constant stress clash (dactylic and spondaic) or arrhythmy in the form of constant stress lapse (iambic). Each of these properties is phonological, and in this way we have described the major components of Greek meter purely in terms of phonology, as promised in the introduction.

We also tried to show that markedness plays a central role in differentiating Greek meters. While there is a rhythmically unmarked meter (the anapest), other meters are distinctively arrhythmic, violating NOCLASH or NOLAPSE. Our answer to the question, "How can such different meters all be rhythmic?" is that they are not.

And we have tried to show that while there is a meter that is unmarked in terms of binarity, namely dimeter, other meters are marked in this respect. Trimeters, tetrameters, and so on violate binarity at various levels 
and to various degrees to provide the poet with distinct, and distinctive, line lengths.

In all of this we were able to give surface-true characterizations of each meter, based strictly on the phonology of Greek. Our analysis is nonderivational and makes no use of ad hoc rules like CONTRACTION or RESOLUTION. Nor is it unnecessarily abstract. We do not claim that the meter is one thing deep down and quite another on the surface. Rather, we claim that a small number of surface-true properties relating to things like rhythm, binarity, and faithfulness are enough to define and differentiate the various meters we find in this language and, we hope, in others.

Received 14 December 1998

Revised version received 27 July 1999
California State University Fresno Stockholm University

\section{Notes}

* Correspondence address: Chris Golston, Department of Linguistics, California State University Fresno, Fresno, CA 93740, USA; E-mail: chrisg@csufresno.edu; Tomas Riad, Department of Scandinavian Languages, Stockholm University, S-10691 Stockholm, Sweden; E-mail: tomas.riad@nordiska.su.se.

1. On free verse, see Riad (1996), who treats it as rhythmic but not metrical.

2. Some twentieth-century poetry parts company with tradition here. Thus, it is not immediately obvious that Gertrude Stein's Tender Buttons (1914) is concerned first and foremost with meaning, as a snippet shows.

\section{A CARAFE, THAT IS A BLIND GLASS.}

A kind in glass and a cousin, a spectacle and nothing strange a single hurt color and an arrangement in a system to pointing. All this and not ordinary, not unordered in not resembling. The difference is spreading.

We currently have no proposals on how syntax, semantics and prosody interact in this type of poetry.

3. For discussion of the prosodic hierarchy, see Selkirk (1986, 1995), Hayes (1989), Nespor and Vogel (1986), and the collection of papers in Inkelas and Zec (1990). Hayes (1989) provides the first evidence for the prosodic hierarchy in meter.

4. The parallels between metrical and prosodic structures seem to be very strict at the bottom (one moraic trochee per metrical position) and top (one intonational phrase per line) and somewhat looser in the middle (roughly one prosodic word per verse foot, roughly one phonological phrase per metron). For a careful quantitative study of these units in Italian verse, see Helsloot $(1995,1997)$. We concentrate here on the lower parts of the hierarchy (foot and word) where the patterns are the clearest.

5. "Poets normally avoid placing unelidable vowels before a word beginning with a vowel" (West 1982: 11). 
6. Cf. Maas (1962: section 34), who notes that "we have to reckon with the possibility that even a short final syllable may have been made prosodically long by the presence of a pause after it."

7. This is a proper subset of those used in Hanson and Kiparsky (1996); we do not know if our smaller set of verse feet will account for the Finnish data there.

8. The only other realizational possibility in this position would be LLLL.

9. We have one piece of evidence but are unclear on how to interpret it. There is a fairly regular word break after the fourth and eighth surface positions (West 1982: 94). If it were common to cut the line up along the edges of metra, this might be taken as evidence for the type of analysis in (30). But in most Greek meters the main breaks in the line occur within metra, not at their edges, and a division of lines into equal lengths is strictly avoided (Allen 1973: 18; Prince 1989). Thus the main line break always occurs within a metron in dactylic hexameter and in iambic trimeter. This would argue for an analysis of tetrameter along the lines of (31).

10. Nonbranching intonational phrases (monometers) are very rare in Greek and never constitute runs, systems, or the like. We exclude them with a constraint that requires intonational phrases to branch at least once.

11. Prince (1990) proposes a single constraint that requires feet to be binary on a moraic or a syllabic analysis. We have split the two issues in order to reflect the difference between moraic and syllabic trochees. We assume that languages with syllabic trochees respect FTBIN- $\sigma$; languages with moraic trochees respect FTBIN- $\mu$.

12. For lapse avoidance in English meter see Hayes and Kaun (1996), Golston (1998), Hayes and McEachern (1998); for lapse avoidance in Arabic see Golston and Riad (1997).

13. Trimeters of roughly this type occur in the poetry of the Italian twentieth-century poets Ungaretti and Montale as well; the commonest type of line in these authors (7- and 11-syllable lines) are typically parsed into three phonological phrases (Helsloot 1995: 48ff.).

14. Devine and Stephens (1994: 399) make a similar count and arrive at a similar conclusion. Counting appositive groups only (i.e. disregarding function words) they find 2-3 per half-line.

15. A Classical Arabic meter of exactly this type, mutaqārib, is discussed in Golston and Riad (1997).

16. Prince (1989) also contains an analysis of the meters of Classical Arabic. A critical discussion of those results can be found in Golston and Riad (1997), where the Arabic data is reanalyzed with the same set of nine verse feet used above in (21).

\section{References}

Allen, W. Sidney (1968). Vox Graeca. Cambridge: Cambridge University Press.

-(1973). Accent and Rhythm. Prosodic Features of Latin and Greek: A Study in Theory and Reconstruction. Cambridge: Cambridge University Press.

Arnold, E. V. (1905). Vedic Metre. Cambridge: Cambridge University Press.

Bailey, J. (1968). The basic structural characteristics of Russian literary meters. In Studies Presented to Professor Roman Jakobson by his Students, C. E. Gribble (ed.), 17-38. Cambridge, MA: Slavica.

Bers, Victor (1984). Greek Poetic Syntax in the Classical Age. New Haven: Yale University Press. 
Burling, R. (1966). The metrics of children's verse: a cross-linguistic study. American Anthropologist 68, 1418-1441.

Creed, Robert Payson (1990). Reconstructing the Rhythm of Beowulf. Columbia and London: University of Missouri Press.

Devine, A. M.; and Stephens, L. (1978). The Greek appositives: toward a linguistically adequate definition of caesura and bridge. Classical Philology 73(4).

-; and Stephens, L. (1981). Bridges in the Iambographers. Greek, Roman and Byzantine Studies 22(4).

-; and Stephens, L. (1983). Semantics, syntax, and phonological organization in Greek: aspects of the theory of metrical bridges. Classical Philology 78(1).

-; and Stephens, L. (1994). The Prosody of Greek Speech. New York: Oxford University Press.

Dover, Kenneth (1997). The Evolution of Greek Prose Style. New York: Oxford University Press.

Fitzgerald, Colleen M. (1994). Prosody drives the syntax: O'odham rhythm. Unpublished manuscript, University of Arizona.

- (1995). Poetic meter » morphology in Tohono O'odham. Paper presented at the annual meeting of the Linguistic Society of America, New Orleans.

- (1998). The meter of Tohono O'odham songs. International Journal of American Linguistics 64(1), 1-36.

Friedberg, Nila (1997). Optimal meter and Russian verse. Unpublished manuscript, University of Toronto.

Getty, Michael (1998). A constraint-based approach to the meter of Beowulf. Unpublished doctoral dissertation, Stanford University.

Golston, Chris (1990). Minimal word, minimal affix. In Proceedings of the 21st Annual Meeting of the North-East Linguistics Society, Tim Sherer (ed.). Amherst, MA: GLSA.

-(1991). Both lexicons. Unpublished doctoral dissertation, UCLA.

- (1995). Syntax outranks phonology. Phonology 12(3), 343-368.

- (1996). Direct optimality theory: representation as pure markedness. Language 72(4), 713-748.

-(1998). Constraint-based metrics. Natural Language and Linguistic Theory 16(4), $719-770$.

-; and Riad, Tomas (1995). Direct metrics. Paper presented at the Annual Meeting of the Linguistic Society of America, San Diego. Unpublished manuscript, California State University Fresno and Stockholm University.

-; and Riad, Tomas (1997). The phonology of Classical Arabic meter. Linguistics 35, $111-132$.

-; and Riad, Tomas (1998). Äldre germansk vers är kvantifierande. Proceedings of the University of Vaasa. Reports 30: Meter Mål Medel. Studier framlagda vid Sjätte nordiska metrikkonferensen med temat "Metrik och dramatik," Vasa 25-27.9.1997, Marianne Nordman (ed.), 52-70.

-; and Riad, Tomas (1999). Greek lyric meter. Paper presented at the Annual Meeting of the Linguistics Society of America, Los Angeles.

Halle, Morris; and Keyser, Samuel J. (1971). English Stress: Its Form, its Growth, and its Role in Verse. New York: Harper and Row.

-; and Keyser, Samuel J. (1977). The rhythmic structure of English verse. Linguistic Inquiry $8,189-247$.

-; and Vergnaud, Jean-Roger (1980). Three dimensional phonology. Journal of Linguistic Research 1, 83-105.

Hammond, Michael (1991). Poetic meter and the arboreal grid. Language 67, 240-259. 
Hanson, Kristin; and Kiparsky, Paul (1996). A parametric theory of poetic meter. Language 72(2), 287-335.

Hayes, Bruce (1988). Metrics and phonological theory. In Linguistics, the Cambridge Survey, vol. 2: Linguistic Theory: Extensions and Implications, Frederick J. Newmeyer (ed.), 220-249. Cambridge: Cambridge University Press.

-(1989). The prosodic hierarchy in meter. In Rhythm and Meter, Paul Kiparsky and Gilbert Youmans (eds.), 201-260. San Diego, CA: Academic Press.

-(1995). Metrical Stress Theory. Principles and Case Studies. Chicago: University of Chicago Press.

-; and Kaun, Abigail (1996). The role of phonological phrasing in sung and chanted verse. Linguistic Review 13, 243-303.

-; and McEachern, Margaret (1998). Quatrain form in English folk verse. Language $74(3), 473-507$.

Helsloot, Karijn (1995). Metrical Prosody: A Template-and-Constraint Approach to Phonological Phrasing in Italian. HIL dissertations 16. The Hague: Holland Academic Graphics.

- (1997). Poetic meter is metrical prosody: phonological phrasing in Italian bound and free verse. In Certamen Phonologicum III, P. M. Bertinetto et al. (eds.), 111-135. Turin: Rosenberg and Sellier.

Inkelas, Sharon; and Zec, Draga (eds.) (1990). The Phonology-Syntax Connection. Chicago: University of Chicago Press.

Jakobson, Roman (1933). Über den versbau der serbokroatischen Volkskepen. Archives Néerlandaises de Phonétique Expérimentale 9-10. (Reprinted [1966]. In Selected Writings. The Hague: Mouton.)

-(1952). Slavic epic verse: studies in comparative metrics. Oxford Slavonic Papers 3, 21-66. (Reprinted [1966]. In Selected Writings. The Hague: Mouton.)

- (1966). Selected Writings, vol. 4: Slavic Epic Studies. The Hague: Mouton.

Kager, René (1989). A Metrical Theory of Stress and Destressing in English and Dutch. Dordrecht: Foris.

-(1993). Alternatives to the iambic-trochaic law. Natural Language and Linguistic Theory $11,381-432$

Kiparsky, Paul (1968). Metrics and morphophonemics in the Kalevala. In Studies Presented to Professor Roman Jakobson by his Students, C. E. Gribble (ed.), 137-148. Cambridge, MA: Slavica.

-(1975). Stress, syntax, and meter. Language 51, 576-616.

- (1977). The rhythmic structure of English verse. Linguistic Inquiry 14, 357-393.

- (1991). Catalexis. Unpublished manuscript, Stanford University/Wissenschaftskolleg zu Berlin.

Kozasa, Tomoko (1998). Meter or rhythm: moraic tetrameter in Japanese poetry. Unpublished manuscript, University of Hawai'i at Manoa.

Liberman, Mark (1975). The intonational system of English. Unpublished doctoral dissertation, MIT. (Distributed by Indiana University Linguistics Club.)

-; and Prince, Alan S. (1977). On stress and linguistic rhythm. Linguistic Inquiry 8, 249-336.

Lotz, John (1960). Metric typology. In Style in Language, Thomas A. Sebeok (ed.). Cambridge, MA: MIT Press.

Ludwich, A. (1885). Aristarchs Homerische Textkritik nach den Fragmenten des Didymos, II. Leipzig.

Maas, Paul (1962). Greek Metre, Hugh Lloyd-Jones (trans.). Oxford: Clarendon. 
McCarthy, John J.; and Prince, Alan S. (1990). Foot and word in prosodic morphology: the Arabic broken plural. Natural Language and Linguistic Theory 8, 209-282.

-; and Prince, Alan S. (1993a). Prosodic morphology I. Unpublished manuscript, University of Massachusetts, Amherst, and Rutgers University.

-; and Prince, Alan S. (1993b). The emergence of the unmarked. Unpublished manuscript, University of Massachusetts, Amherst, and Rutgers University.

-; and Prince, Alan S. (1993c). Generalized alignment. Yearbook of Morphology, 79-153.

Mester, R. Armin (1994). The quantitative trochee in Latin. Natural Language and Linguistic Theory 12, 1-61.

Nagy, Gregory (1974). Comparative Studies in Greek and Indic Meter. Cambridge, MA: Harvard University Press.

Nespor, Marina; and Vogel, Irene (1982). Prosodic domains of external sandhi rules. In The Structure of Phonological Representations, part 1, Harry van der Hulst and Norval Smith (eds.). Dordrecht: Foris.

-; and Vogel, Irene (1986). Prosodic Phonology. Dordrecht: Foris.

-; and Vogel, Irene (1989). On clashes and lapses. Phonology 6, 69-116.

Page, D. L. (ed.) (1962). Poetae Melici Graeci. Oxford: Clarendon.

Piera, C. (1980). Spanish verse and the theory of meter. Unpublished doctoral dissertation, UCLA.

Postgate, J. P. (1924). A Short Guide to the Accentuation of Ancient Greek. London.

Prince, Alan S. (1989). Metrical forms. In Rhythm and Meter, Paul Kiparsky and Gilbert Youmans (eds.), 45-80. San Diego, CA: Academic Press.

- (1990). Quantitative consequences of rhythmic organization. Chicago Linguistic Society 26, 355-398.

-; and Smolensky, Paul (1993). Optimality theory: constraint interaction in generative grammar. Unpublished manuscript, Rutgers University and University of Colorado, Boulder.

Prokosch, Eduard (1939). A Comparative Germanic Grammar. Linguistic Society of America. Philadelphia: University of Philadelphia Press.

Raven, D. S. (1962). Greek Metre. London: Faber and Faber.

Riad, Tomas (1992). Structures in Germanic prosody: a diachronic study with special reference to the Nordic languages. Unpublished doctoral dissertation, Stockholm University.

- (1996). Betoning och rytm i fri vers. Ernst Brunners Konstpaus. In Stilstudier, Olle Josephson (ed.). Stockholm: Hallgren and Fallgren.

Rice, Curt (1997a). Phonology outranks morphology: Chaucerian past participles and the grammar of poetry. Talk presented at HILP 3, Amsterdam. Unpublished manuscript, University of Tromsø.

- (1997b). Ranking components: the grammar of poetry. In Phonology in Progress Progress in Phonology, Geert Booij and Jeroen van de Weijer (eds.), 321-332. The Hague: Holland Academic Graphics.

- (1997c). Generative metrics. GLOT International 2(7), 3-7.

-; and Svenonius, Peter (1997). Prosodic V2 in Northern Norwegian. Talk presented at the Hopkins Optimality Theory Workshop and Maryland Mayfest, Baltimore. Unpublished manuscript, University of Tromsø.

Sauzet, Patrick (1989). L'accent du grec ancien et les relations entre structure métrique et réprésentation auto-segmentale. Langages 95, 81-113.

Selkirk, Elizabeth O. (1978). On prosodic structure and its relation to syntactic structure. In Nordic Prosody II, T. Fretheim (ed.). Trondheim: Tapir. 
- (1980). Prosodic domains in phonology: Sanskrit revisited. In Juncture, Mark Aronoff and Mary-Louise Kean (eds.). Saratoga, CA: Anma Libri.

- (1981). On the nature of phonological representations. In The Cognitive Representation of Speech, J. Anderson, J. Laver, and T. Myers (eds.). Amsterdam: North-Holland.

-(1984). Phonology and Syntax. Cambridge, MA: MIT Press.

- (1986). On derived domains in sentence phonology. Phonology Yearbook 3, 371-405.

- (1995). The prosodic structure of function words. In Papers in Optimality Theory, Jill N. Beckman, Laura Walsh Dickey, and Suzanne Urbanczyk (eds.), 439-470. University of Massachusetts Occasional Papers 18. Amherst: GLSA.

Sommerstein, A. H. (1973). The Sound Pattern of Ancient Greek. Oxford.

Steriade, Donca (1982). Greek prosodies and the nature of syllabification. Unpublished doctoral dissertation, MIT.

Stockwell, Robert P.; and Minkova, Donka (1997). Prosody. In A Beowulf Handbook, John Niles and Robert Bjork (eds.), 55-85. Lincoln: University of Nebraska Press.

Vendryes, J. (1945). Traité d'accentuation grecque. Paris.

Venneman, Theo (1988). Preference Laws for Syllable Structure and the Explanation of Sound Change. Berlin: Mouton.

Wackernagel, J. (1914). Akzentstudien II. Nachrichten der göttingischen Gesellschaft der Wissenschaften 20. Göttingen.

Weil, Gotthold (1960). Garūd I. In Encyclopedia of Islam, 2nd ed., 667-677. Leiden: Brill.

West, M. L. (1982). Greek Metre. Oxford: Oxford University Press.

Youmans, Gilbert (1983). Generative tests for generative meter. Language 59, 67-92.

- (1989). Milton's meter. In Rhythm and Meter, Paul Kiparsky and Gilbert Youmans (eds.), 341-379. San Diego, CA: Academic Press. 